\title{
Innovation and Entrepreneurship: The Necessary Conditions of Value Creation
}

\author{
Brian BARNARD ${ }^{1 *}$ and Derrick HERBST ${ }^{2}$ \\ ${ }^{1}$ Wits Business School, University of Johannesburg, South Africa \\ ${ }^{2}$ Henley Business School South Africa, University of Reading, South Africa
}

\begin{abstract}
The necessary conditions of value creation are considered from the vantage point of innovation and entrepreneurship. Both demand side (basic needs, customer perceived value, and customer satisfaction) and supply side (science, technology, and knowledge) considerations of value creation are examined. The relationships between value creation and basic needs, customer perceived value, and knowledge are further examined. Although a number of factors are identified that impact value, only four are seen as primary factors of value: price, benefit, satisfaction, and experience. The innovator and entrepreneur can create value, and quantify the uniqueness of their value offerings, through these four primary factors. The study concludes that, on the demand side, basic needs may be an indirect driver of value creation, and customer perceived value as concept may be useful in the context of value creation. At the same time, it is believed that the four factors - price, benefit, satisfaction, and experience - can significantly explain value creation. On the supply side, innovation as the driver of value creation, is not necessarily confined to science and technology - business knowledge and acumen is an important avenue. In addition to existing knowledge and experience, factors like orientation (interests, passion, drive) and involvement also explain opportunity recognition.
\end{abstract}

Keywords: Innovation, entrepreneurship, value creation, opportunity, opportunity recognition, knowledge, incremental innovation, radical innovation, innovation measurement and evaluation, missing value, uniqueness of value, basic needs, entrepreneurship development

JEL Classification: O30, L26

\section{Introduction}

\subsection{Demand Side Considerations of Value Creation}

Sinha and DeSarbo (1998) note that the notion of value is central to economic exchange and endemic to marketing, in which ideally both the buyer and seller infer a value greater than each gives up; that is, both parties are economically the gainer because each receives something more useful to him or her than what he or she has relinquished.

\footnotetext{
${ }^{*}$ Corresponding Author:

Brian Barnard, Wits Business School, University of Johannesburg, Johannesburg, South Africa

Article History:

Received 18 September 2017 | Accepted 19 October 2017 | Available Online 28 October 2017

Cite Reference:

Barnard, N. and Herbst, D., 2017. Innovation and Entrepreneurship: The Necessary Conditions of Value Creation. Expert Journal of Business and Management, 5(2), pp.98-128.
} 


\subsubsection{Human Motivation and Basic Needs}

Chulef et al (1991) created a taxonomy of human goals, based on a list of 135 such goals. In sum, for the total sample, goals fell into three major clusters: 1) family, marriage, sex, and romance; 2) interpersonal goals related to interacting with people in general; and 3) intrapersonal goals. The general interpersonal goals then subdivided into a number of other subclusters, such as physical goals including health and appearance, goals related to friendship, belonging, social recognition, and social approval, and several clusters of goals related to receiving from others, avoiding rejection, general positive social qualities (such as being respected and being honest), teaching and helping others, and leadership. The intrapersonal goals also subdivided into a number of subclusters, such as a set consisting of various clusters related to freedom, ethics, social awareness, and religion; another set containing clusters related to aesthetics, creativity, entertainment, and openness to experience; a third set related to psychological well-being, safety and stability, personal growth, achievement and self-determination; and a final set with clusters concerning finances, career, and education and intellect.

In discussing value methodology, Kahle et al (1986) list nine values: self-respect, security, warm relationships with others, sense of accomplishment, self-fulfillment, sense of belonging, being well respected, fun and enjoyment in life, and excitement.

Bernard et al (2005) in turn list 15 human motives as goals: 1) creativity, flexibility, openness and excitement; 2) stability and safety; 3) entertainment; 4) physical health; 5) sex and romance; 6) physical appearance; 7) finances; 8) intellect and education; 9) aesthetics; 10) physical health; 11) marriage and family; 12) friendship, receiving from others; 13) social awareness; 14) defense versus rejection, positive social qualities, ethics and idealism; 15) Teaching and helping others; religion; higher meaning, personal growth.

Alkire (2002) compares the development dimensions of Nussbaum (2000), Narayan et al (2000),

Schwartz, Cummins, Ramsay, Doyal and Gough (1991):

- Nussbaum (2000): Life; bodily health; bodily integrity; senses, imagination, thought; emotions; practical reason; affiliation; other species; play; control over one's environment - a) political, b) material.

- Narayan et al (2000): a) material well-being: having enough food, assets, work; b) bodily well-being: being and appearing well; health, appearances, physical environment; c) social well-being: being able to care for, bring up, marry and settle children; self-respect and dignity; peace, harmony, good relations in the family/ community; d) security: civil peace; a physically safe and secure environment; personal physical security; lawfulness and access to justice; security in old age; confidence in the future; e) freedom of choice and action; f) psychological well-being: peace of mind; happiness; harmony (including a spiritual life and religious observance).

- Schwartz (1992): power; achievement; hedonism; stimulation; self-direction; universalism; benevolence; tradition; conformity; security.

- Cummins: material well-being, health, productivity, intimacy/ friendship, safety, community, and emotional well-being.

- Ramsay: physical; survival; sexual needs; security; love and relatedness; esteem and identity; and selfrealization.

- Doyal and Gough (1991): nutritional food/ water; protective housing; work; physical environment; health care; security in childhood; significant primary relationships; physical security; economic security; safe birth control/ childbearing; basic education.

- Flint et al (1997) argue that individual values extends to organizational values.

\subsubsection{Perceived Value}

With regards to value types, Sheth et al (1991) identify five consumption values influencing consumer choice behavior: 1) functional value, 2) social value, 3) emotional value, 4) epistemic value, and 5) conditional value. Holbrook (1994) suggests customer value may be intrinsic or extrinsic to the product, and it may be self-oriented or other-oriented.

Sweeney and Soutar (2001) differentiate between perceived value and consumer satisfaction. While perceived value occurs at various stages of the purchase process, including the prepurchase stage, satisfaction is universally agreed to be a postpurchase and postuse evaluation. As a consequence, value perceptions can be generated without the product or service being bought or used, while satisfaction depends on experience of having used the product or service. Woodruff (1997) concurs: purchase means choosing, and that requires customers to distinguish between product offer alternatives and evaluate which is preferred. In contrast, during or after use, customers are more concerned with performance of the chosen product in specific use situations.

Woodruff (1997) notes that customer value is something perceived by customers, rather than 
objectively determined by a seller. These perceptions typically involve a trade-off between what the customer receives and what he gives up to acuire and use a product. In differentiating between desired value and received value, it is noted that customers imagine what value they want - desired value - either prior to purchase, or later at the time of use. Customers think concretely about value in the form of preferred attributes, attribute performances, and consequences from using a product in a use situation. In addition, they form evaluative opinions or feelings about the actual value experience of using a product - received value. During the choice task, customers may predict received value, but during use they actually experience received value. Flint et al (1997) define desired value as the customers' perception of what they want to have happen (i.e., the consequences) in a specific kind of use situation, with the help of a product or service offering, in order to accomplish a desired purpose or goal. Desired value can take on two aspects: value in use or possession value. Value in use reflects the use of the product or service in a situation to achieve a certain goal or set of goals. Possession value reflects the inherent meaning of the product or service to the customer.

Patterson and Spreng (1997) note the most common definitions of value in marketing literature: a) a ratio or trade-off of total benefits received to total sacrifices, b) a comparison of weighted "get" attributes to "give" attributes, c) the functional definition - defining value in terms of performance (quality) and price. Chen and Quester (2005) note two primary thoughts on value: 1) the rational perspective of value, and 2) the experiential perspective of value. The rational perspective of value is a kind of return for paying for a commodity, and such return involves an assessment of the trade-off or a comparison of benefits and sacrifices (the monetary and non-monetary costs) in terms of the consumption experience. By contrast, the experiential perspective of value places an emphasis on the personal and subjective perception such as emotion or preference. This experiential perspective is phenomenological in spirit and regards consumption as a primarily subjective state of consciousness with a variety of symbolic meanings, hedonic responses, and esthetic criteria. Both perspectives are equally important to comprehend value in consumption experiences.

As part of a means-end model, Zeithaml (1988) defines perceived value in terms of perceived quality, perceived sacrifice, intrinsic and extrinsic attributes, and high-order abstractions.

Ravald and Grönroos (1996) note that customer-perceived value is defined as the ratio between perceived benefits and perceived sacrifice. The perceived sacrifice includes all the costs the buyer faces when making a purchase: purchase price, acquisition costs, transportation, installation, order handling, repairs and maintenance, risk of failure or poor performance. The perceived benefits are some combination of physical attributes, service attributes and technical support available in relation to the particular use of the product, as well as the purchase price and other indicators of perceived quality.

Yang and Peterson (2004) propose that perceived value is rooted in equity theory, which considers the ratio of the consumer's outcome/ input to that of the service provider's outcome/ input. The equity concept refers to customer evaluation of what is fair, right, or deserved for the perceived cost of the offering. Yang and Peterson (2004) state that "perceived costs include monetary payments and nonmonetary sacrifices such as time consumption, energy consumption, and stress experienced by consumers. In turn, customer perceived value results from an evaluation of the relative rewards and sacrifices associated with the offering. Customers are inclined to feel equitably treated if they perceive that the ratio of their outcome to inputs is comparable to the ratio of outcome to inputs experienced by the company." Also, customers tend to measure an organization's ratio of outcome to inputs by making comparisons with its competitors' offerings.

Snoj et al (2004) note that the utility theory approach stresses that very often customers do not buy products (i.e. goods, services) for their own sake. They buy bundles of attributes which derive value according to the utility (benefits) provided by the combination of attributes less the disutility represented by their sacrifices in obtaining the product. In other words, the value is conceptualized as a customer's perceived net trade-off received from all relevant benefits and costs or sacrifices delivered by a product or service or supplier and its use. Perceived benefits are a combination of different attributes of products (tangible and intangible; intrinsic and extrinsic etc.), available in relation to a particular buy and use situation. Perceived sacrifices are a combination of nominal price and all other costs of product acquisition and its use. Perceived sacrifices have a negative effect on perceived value of products, and involve not only the nominal price, but also the nonmonetary aspects of price - the monetary costs, opportune costs, energy costs and psychical cost. They also include perceived risk - consumer behavior involves risk in that any action of a consumer may produce consequences which he cannot anticipate with any approximating certainty, and some of those at least are likely to be unpleasant. They define it to entail multiple types of risks, including financial, functional, physical, psychological, social and time risk.

Woodruff et al (1993) note the attribute concept of value: customer value is a trade-off between desireable attributes - that which is desired from the seller - compared to sacrifice attributes - that which is given up to buy and use the product. Price and most other cost dimensions, such as complexity of product 
operation, can be incorporated into attribute value as well. Further, even though there is merit in it, the attributebased view of value has a distinctly product, rather than customer orientation. It assumes that customer value is largely determined by what is designed into products and services. Customers consider attributes, as well as use situations, benefits sought from those situations, and purposes for using the product. Attributes link to benefits, which in turn link to purpose, to form a value chain. They note that products may also have declining value - customers may actively accentuate negative aspects of the product to demonstrate how unsuitable it was for specific use situations. Also, the value that consumers associate with a product changes over time.

\subsubsection{Customer Satisfaction}

Snoj et al (2004) note the tendency to concentrate customer value on product quality and nominal price. According to this thinking, bundles of attributes together represent a certain level of quality, which therefore provide utility to the customer. The benefits are measured through a perceived level of quality (level of working superiority), a bundle of attributes in comparison with the consumer's expectations. Perceived quality is defined as the consumers' judgement about overall excellence or superiority. It differs from objective quality, which involves an objective aspect or feature of a thing or event.

Oliver (1980) state that satisfaction is a function of an initial standard and some perceived discrepancy from the initial reference point. The effects of expectation and discrepancy perceptions may be additive. Specifically, expectations are thought to create a frame of reference about which one makes a comparative judgment. Thus, outcomes poorer than expected (a negative disconfirmation) are rated below this reference point, whereas those better than expected (a positive disconfirmation) are evaluated above this base. Expectations are impacted by 1) the product itself, including one's previous experience, brand associations, and symbolic elements, (2) the context, including the content of communications from salespeople and social referents, and (3) individual characteristics, including the ability to persuade and perceptual distortion. Postdecision deviations from the adaptation level are thought to be caused by the degree to which the product exceeds, meets, or falls short of one's expectations - positive, zero, or negative disconfirmation. Satisfaction interacts with other cognitions of an emotional nature. Revised postpurchase attitude is a function of prepurchase attitude, and immediate postpurchase satisfaction disconfirmation as a cognitive comparison between anticipated and received satisfaction. It is a disconfirmation at the more abstract affect level rather than at the more objective attribute level.

Fournier and Mick (1999) point out principal satisfaction models as: 1) the disconfirmation of preconsumption product expectations, 2) desires based on features and benefits that are considered ideal or aspirational in the product domain, 3) equity expectations, and 4) experience-based norms. Thus, in addition to the cognitive nature of satisfaction, the affective nature of satisfaction is also pointed out.

Woodruff et al (1993) note that, firstly, value and satisfaction tend to be interwoven in consumers' thoughts about product experiences. Satisfaction is an immediate reaction to how much value was received from using a product in specific use situations. Consumers can have varying degrees of satisfaction with attribute performance and/ or with benefits received from using the product in a situation. Secondly, consumers compare what value they received from a product to some kind of standard. Satisfaction is an evaluation feeling about this comparison. Types of standards may also include: promises made by the seller, performance received from another brand, the performance desired, the performance experienced by another person, and performance from another type of product. Also, consumers experience emotions of different intensity with satisfaction evaluation. Similarly, Anderson and Sullivan (1993) model satisfaction as a function of perceived quality and disconfirmation, with expectations influencing perceived quality.

In stressing the affective nature of satisfaction, Babin and Griffin (1998) note that consumer satisfaction can be described as an emotion resulting from appraisals (including disconfirmation, perceived performance, etc.) of a set of experiences. Bigné et al (2005) expand cognitive-affective theory further by noting the dimensional approach to explaining emotions. Two dimensions of emotions are introduced: arousal and pleasure. Pleasure refers to the degree to which a person feels good, joyful or happy in a situation; arousal refers to the extent to which a person feels stimulated and active.

Moliner et al (2007) reflect on the cognitive nature (comparing expectations and performance) and the affective nature (associated feeling of pleasure) of satisfaction. According to the disconfirmation paradigm, satisfaction is a comparison between performance and expectations. But this is a definition based on what the consumer does, and not on its psychological meaning. It is therefore proposed that satisfaction is defined as pleasurable fulfilment. That is, the consumer senses that consumption fulfils some need, desire, goal, etc., and that this fulfilment is pleasurable. Thus, satisfaction is the consumer's sense that consumption provides outcomes against a standard of pleasure versus displeasure. Correspondingly, $\mathrm{Xu}$ et al (2007) describe customer satisfaction as a pleasurable level of consumption-related fulfilment. Customer satisfaction is 
generally conceptualized as an attitude-like judgement following a series of purchases or consumer-product interactions. It is understood as the customer's emotional reaction to the perceived difference between performance appraisal and expectation.

Szymanski and Henard (2001) and Halstead et al (2007) model the antecedents of customer satisfaction as expectations, disconfirmation of expectations, performance, affect, and equity. Consumer expectations as anticipation imply that expectations have a direct influence on satisfaction. Disconfirmation of expectations refer to the conceptualization of expectations as the standard against which performance outcomes are assessed. In addition to performance as a component of disconfirmation, performance is modelled as directly affecting satisfaction. Affect relays the possibility that satisfaction is not just cognitive, but includes an affective component. Equity is a fairness, rightness, or deservingness judgement that consumers make in reference to what others receive.

Spreng et al (1996) model satisfaction as a function of attribute satisfaction, perceived performance, as well as information satisfaction. Expectations and desires both impact expectation disconfirmation and desires disconfirmation, respectively. Expectation disconfirmation and desires disconfirmation in turn affect attribute and information satisfaction. Information satisfaction is defined as a subjective satisfaction judgement of the information used in choosing a product. Expectations are seen as beliefs about the likelihood that a product is associated with certain attributes, benefits, or outcomes, whereas desires are evaluations of the extent to which those attributes, benefits or outcomes lead to the attainment of a person's values.

Gardial et al (1994) further expand on evaluative criteria, product referents, comparison to standards, and evaluation outcomes and emotion responses, in the context of prepurchase and postpurchase evaluations.

According to Sweeney and Soutar (2001), satisfaction has been conceptualized as a unidimensional construct, largely due to the assumption that it varies along a hedonic continuum from unfavorable to favorable and to its conceptualization as a consequence, outcome or summary variable in comparison to value, which is antecedent to it. In contrast, value should be conceptualized as a multidimensional construct.

Homburg et al (2005) and Fournier and Mick (1999) differentiate between transaction-specific satisfaction and cumulative satisfaction. Transaction-specific satisfaction is a customer's evaluation of his or her experience with and reactions to a particular product transaction, episode, or service encounter, and cumulative satisfaction refers to the customer's overall evaluation of a product or service provider to date. Given that comparison standard are likely to change with consumer experience, satisfaction is unlikely a static evaluation derived from a lone-trial event, but a process extending across the entire consumption horizon.

\subsection{Supply Side Considerations of Value Creation}

The following sections look at the difference between science and technology; the interaction between science and technology; the economic and geographical attributes of science and technology; innovation through science and technology; convergence; paradigms, trajectories and search paths; and the social aspects of science and technology.

\subsubsection{Science, Technology and Innovation}

Rip (1992) notes the myths of science and technology: the science goose always lays golden eggs when fed properly; technology is the means to achieve, supposedly in an unproblematic way, whatever we want.

Heilprin (1995) defines the object of science as the representation of reality. Its methods produce, through sense perception and logic, systems of mental classes, categories, groups and attributes or single properties. New categories and subcategories tend to grow from the bottom, from the concrete to the abstract. Highly abstract classes tend to change more slowly. Deductive and inductive logic are involved in updating systems of mental classes. According to Ahuja and Katila (2004), science is the establishment of facts and the development of quantitative rules or laws that relate those facts to each other. The main purpose of science is creating new knowledge and solving fundamental problems while developing scientific laws and theories that describe and explain the causes and effects of nature's phenomena (Lee et al, 2016).

According to Hong (1999), the essence of technology lies in technological knowledge, rather than in the hardware. Keller (2008) sees technology as a knowledge system rather than an application per se or a device, based on the view that technology implies the knowledge of how to use the resources and forces of nature to fulfil certain human purposes. Rip (1992) notes the view that science is knowledge and technology is artefacts should be re-evaluated. A continuum rather than a categorical difference likely apply. Knowledge claims rather than knowledge are used: statements which include the claim that the insight or effect is applicable in other situations, including the situation at hand. Also, artefacts are not just contraptions, but a promise of functionality provided one embeds and uses the artefact in the right way. 
Adams (1997) views technology as intimately embedded in the entire field of forces constituting society at large. The frame in which it is conceived, modified, and put to diverse uses before giving way to something better is in the end almost indistinguishable from the larger set of algorithms society is continually devising to carry out its objectives. In this much more interactive and inclusive sense, technology is better thought of as a set of partly distinct, partly overlapping sociotechnical systems whose precise content and boundaries are intentionally left ill-defined.

The difference between science and technology: Contrasted with the craftsmen tradition of technology, science has a philosophical tradition. Natural science was developed from natural philosophy (Cao, 2015). Science aims to provide an elucidation of natural phenomenon, while the purpose of technology is to create artefacts (Suenaga, 2016). The goal of scientific activities is to enhance knowledge and understanding, or learning for its own sake. Technology, in contrast, is concerned with incorporating such knowledge into physical artefacts that benefit users (Ahuja and Katila, 2004). Discoveries in science focus primarily on the natural worid, while their technological counterparts are largely directed toward a no less rapidly changing material and organizational world of our own design (Adams, 1997). One of the main purposes of academic research is to produce codified theories and models that explain and predict natural reality. To achieve analytical tractability, this requires simplification and reduction of the number of variables. The main purpose of business research and development is to design and develop produceable and useful artefacts. These are often complex, involving numerous components, materials, performance constraints and interactions, and are therefore analytically intractable (Pavitt, 1998).

A division of labour between science and technology is generally possible, given different incentives in terms of action, reward, and survival (Rosenberg and Nelson, 1994; Rip, 1992). Scientists and engineers have different communities (Hong, 1999). Academic institutions dominate advances in science, while business firms dominate advances in technology. Scientists are concerned with the discovery and publication of new knowledge, and they are not concerned with its application. On the other hand, the concern of technologists or engineers is the practical application of knowledge and professional recognition, and not the publication of knowledge. Scientists (or academic institutions) act with the aim of achieving social rewards, such as a reputation, rather than economic rewards, such as profit (Suenaga, 2016). Science dominate in the publication of scientific papers, and business firms in the granting of patents. (Pavitt, 1998). Largely because technological innovation is tied to complex, expensive production processes and marketing uncertainties, it moves at a slower, more cautiously incremental pace than scientific discovery (Adams, 1997).

Advances in science build mainly on already existing scientific knowledge, while advances in technology build mainly on technological knowledge (Suenaga, 2016). Basic research builds mainly on basic research (scientific papers cite other scientific papers much more frequently than patents); and technology builds mainly on technology (patents cite other patents much more frequently than scientific papers) (Pavitt, 1998).

There is a marked difference between scientific knowledge, and the knowledge required for new products at commercial scale (Rosenberg and Nelson, 1994). Output from scientific research is rarely directly applicable when releasing new products in the market. Technological knowledge is better suited to satisfying technological trends and market needs than scientific knowledge (Lee et al, 2016). Scientific knowledge is much more codified than technological knowledge, and much of technological knowledge is implicit in experience and skill. Therefore, scientific knowledge is easier to spread compared to technological knowledge (Suenaga, 2016).

Furthermore, science is not directly economically valued, while technology is (Suenaga, 2016).

According to Faulker (1994), technology and science are distinguished in three areas: 1) purpose or orientation, 2) sociotechnical organization, 3) cognitive and epistemological features. Technology is more practical-artificial oriented, is a more heterogeneous activity, local and tacit knowledge is more important to technology. Even though distinction in methodology is less evident, the way theory is used differs. A learning process is often necessary during design. Cao (2015) contrasts the ontological, epistemological, and methodological differences: In terms of ontology, science represents theoretical discoveries and involves natural objects while technology manifests itself in technological inventions and involves man-made objects, processes, and designs. In terms of epistemology, science and technology can be treated as separate spheres of knowledge, both man-made. Scientific knowledge to know what and know why is theoretical and declarative. Technological knowledge to do what and know how is practical, procedural, autonomous, and descriptive, rather than an application of knowledge. In terms of methodology, science often begins with a set of hypotheses that are subsequently verified or falsified as a result of a process of experimentation. Technology mainly integrates a process of design, invention, creation, and innovations with practical experiences of trial and error.

The interaction between science and technology: Cao (2015) shows that technology emerged much 
earlier than science, initially existing without literacy. The unbalanced development between science and technology is also highlighted. Hong (1999) notes two extreme positions on the relationship between science and technology: 1) science and technology have long been intimately connected and are almost fused into one, to such an extent that any distinction between them is now meaningless; 2) science and technology were, and largely still are, distinct activities, each with its own norms, methods, and communities. Cao (2015) note three basic standpoints with regards to the positional contrast between science and technology: 1) science is superior to technology in a master-servant relationship, 2) science is closely equal to technology, 3) technology is superior to science. The interactive degree between science and technology also has three views: sciencetechnology independence, interaction, and integration.

Price (1965) argues that science and technology are two subsystems which develop autonomously, and he uses the metaphor of two dancing partners that have their own steps although dancing to the same music. Rip (1992) argues that with this metaphor, the dance halls, music, and dancing patterns should not be ignored. Brooks (1994) uses the metaphor of two strands of DNA which can exist independently, but cannot be truly functional until they are paired. Rip (1992) uses a two-branched model to depict the ongoing processes of science and technology. Two different kinds of activity branch from a finding as an unanalysed category for the moment: exploitation (technological development) and exploration (scientific research) to increase understanding. Insights from exploration may be called upon to assist and improve exploitation.

Price (1965) reveals that science and technology have their own separate cumulative structures. With the cumulating, close-knit structure of science, new knowledge flow from highly related and recent pieces of old knowledge. Technology has a similar cumulating, close-knit structure, but of the state of the art, rather than the literature. Since the structures are separate, only in special and traumatic cases involving the breaking of a paradigm can there be a direct flow from the research front of science to that of technology or vice versa. It is probable that research-front technology is strongly related only to that part of scientific knowledge that has been packed down as part of ambient learning and education, not to front science. Similarly, research-front science is related only to the ambient technological knowledge of the previous generation of students, not to the research front of the technological state of the art and its innovations. This reciprocal relation between science and technology, involving the research front of one and the accrued archive of the other, is nevertheless sufficient to keep the two in phase in their separate growths within each otherwise independent accumulation.

Faulkner (1994) notes that science is able to overlap with, and contribute to, technology in the areas of theory, experimental technique, and specialized knowledge, because it had earlier achieved its own momentum. Freeman (1994) note that the contribution made by basic science to industry is mainly indirect, in the form of young recruits with new and valuable skills and knowledge, rather than direct, in the form of published papers. Rosenberg and Nelson (1994) note the contribution of basic research to industry, the potential time lag thereof, and the role of industry maturity; the role of science in development of ways of thinking and specialized methodology design; the impact of basic science on the development of industry professionals; application driven basic research; and the connection and cooperation between universities and industry.

Ahuja and Katila (2004) note that many innovations emerge because they are the locus of a meeting between a problem and its solution, even when neither the problem nor the solution is itself new - resolving existing problems in new ways. Innovations often result from the combination and recombination of known elements of various solutions. Their novelty stems from the act of combination, not necessarily from the individual components that are combined. Innovations can also emerge because they represent some unique genuine novelty; the solution includes components or elements that did not exist earlier, and whose very existence is evidence of novel invention. Over time, unless the elements available for recombination are increased in some fashion, the tempo of innovation must decline as the recombinant search space is exhausted. As the elements in a given technological domain are increasingly exploited and their potential for subsequent new recombination declines. That technological domain must look beyond technology to enrich and reignite the invention process - to science. Science can influence innovative productivity by increasing the number of elements available for combinations. Also, science can improve the inventor's understanding of cause-effect relationships and thus help identify the elements whose combination is likely to be fruitful.

Suenaga, K., A. (2016) classify the relationship between science and technology via five diagrammatic models: 1) Science and technology are independent: existing scientific knowledge advances through scientific research; existing technological knowledge advances through technological development. 2) Science and technology develop autonomously, but are not completely independent. Advances in scientific knowledge bring about advances in technological knowledge. 3) Existing technological knowledge triggers advances in scientific knowledge, and then scientific understanding encourages advances in technology further. 4) There is a close relationship between technological needs and scientific progress: a limit to technological knowledge 
based on existing scientific knowledge instigates a reconsideration of existing scientific knowledge, and produces new scientific knowledge, which allows new technological knowledge to be created. 5) scientific knowledge gives rise to technological paradigms and trajectories.

In the models, science is located in (various layers of) 'soil', because it is not economically valued. The depth of the soil in which the advance in scientific knowledge occur, determines the extensiveness of the technological paradigms formed. Technological paradigms are selected from existing scientific knowledge through economic, institutional, and social factors. If the possibility is high that technological trajectories will develop under a specific technological paradigm, the incentive to look for other technological paradigms decreases. Moreover, if there is a high possibility that scientific knowledge will progress, the possibility that other technological paradigms can be selected increases. The frequency of the emergence of technological paradigms increases as the layer becomes shallower, and the potential for new paradigms increases as the layer becomes deeper. According to the level (soil layer) at which the actor tries to create the technological paradigms, the person, organization, and scientific knowledge required differ.

Pannell (1999) notes that: 1) basic research generates basic knowledge; 2) applied research generates applied knowledge; 3) basic knowledge affects production of applied knowledge by applied research; 4) applied knowledge affects production of basic knowledge by basic research; 5) basic research generates applied knowledge; 6) applied research generates basic knowledge; 7) foreign knowledge contributes to local knowledge; 8) knowledge dissapates or becomes obsolete; 9) knowledge contributes to social welfare. Brooks (1994) notes the contributions of science to technology: 1) science as a direct source of new technological ideas; 2) science as a source of engineering design tools and techniques; 3) instrumentation, laboratory techniques, and analytical methods; 4) the development of human skills; 5) technology assessment; and 6) science as a source of development strategy. On the other hand, the contributions of technology to science are: 1) technology as a source of new scientific challenges; and 2) instrumentation and measurement techniques. According to Pavitt (1998) academic research helps technological problem-solving through: useful knowledge inputs, engineering design tools and techniques, instrumentation, background knowledge, membership of national and international professional networks, and spin-off firms. Some of the interactions of science and technology Faulkner (1994) highlights, are education - the period of training of scientists and technologists, and instrumentalities - the crafts and techniques of the experimentalist and inventor.

Rip (1992) lists three types of connections between science and technology: a laboratory effect or method is exploited for another purpose; a new domain of nature is opened up in the laboratory, and then also available for exploitation; science acting as a powerful source of heuristics for technological search processes. Hong (1999) notes the mediation between science and technology takes place on four levels: between a scientific and a "workshop theory"; between a scientific theory and a practice in the field and in the workshop; between a scientific practice in the lab and a workshop theory; and between a scientific practice in the lab and a practice in the field and the workshop.

Pannell (1999) notes the financial and non-financial benefits of basic research - it contributes to knowledge production, research training, international relations and intellectual culture. The non-financial benefits include contributions to ethics, culture, aesthetics, equity, risk, pure interest (understanding), patriotism (image and reputation), and the environment.

The economic and geographical attributes of science and technology: Even though science may be a public good, it is questioned whether it is a free good, or a pure public good. Brooks (1994) proposes that "substantial research capability (and indeed actual ongoing participation in research) is required to understand, interpret and appraise knowledge that has been placed on the shelf - whether basic or applied". Although academic research has some attributes of a public good (the low cost of transmitting the informational output of the research; no wear and tear on re-use), it is certainly not a free good (intelligible and applicable without cost to the user) (Pavitt, 1998). Countries and companies benefit academically and economically from basic research performed elsewhere only if they belong to the international professional networks that exchange knowledge. This requires (at the very least) high quality foreign research training, and (at the most) a strong world presence in basic research (Pavitt, 1998). Rip (1992) notes that science is not universal by definition, and it takes a lot of effort to decontextualize local findings; technology is not automatically applicable in other situations, and requires work, both on the technology and situations. The main practical benefits of academic research are not easily transmissible information, ideas and discoveries available on equal terms to anyone anywhere in the world. Instead, they are various elements of a problem-solving capacity, involving the transmission of often tacit (i.e., non-codifiable) knowledge through personal mobility and face-to-face contacts. The benefits therefore tend to be geographically and linguistically localised (Pavitt, 1998).

Nelson and Wright (1992) argue that hands-on technological capability is more like a private good than a public good - much of what is involved in mastering a technology is organization-specific investment 
and learning. If technology were a pure public good, as economists are wont to assume in elementary versions of microeconomic theory, then the proposition that firms in certain countries are able to employ technologies that lie beyond the ken of firms elsewhere would make no sense. Technologies are complex, involving different kinds of machines and a variety of learned skills, and often require relatively sophisticated coordination and management. While certain features of these complex operations are described in writing, or more generally are familiar to the experts in the field, to get the technologies under control and operating well generally require a lot of learning-by-doing on the part of many interacting people. Ahuja and Katila (2004) state that, under conditions of perfect information and unlimited rationality, "the existence of knowledge would be sufficient for all firms to be able to use it with equal facility, irrespective of location. Nonetheless, when knowledge diffusion is imperfect and cognition is limited, what matters is not whether a piece of information exists in the world, but rather whether it is part of the cognitive set or knowledge base of the firm when it is needed".

Brooks (1994) distinguishes between originality in the sense of newness to the universe as opposed to newness in context: innovation as the processes by which firms master and get into practice product designs that are new to them, whether or not they are new to the universe, or even to the nation. Ahuja and Katila (2004) note that, "increasingly, research suggests that the technological landscape is differentiated across geographic space. Idiosyncratic national circumstances and institutions induce local, regionally distinctive, and partially insular development of technology resources. Distinctive cultural influences and physical and institutional infrastructures often impose their own pressures and imprints on the avenues that are actively pursued in technological development in any nation. Thus, the precise elements of the technological domain that are addressed and developed in a given nation may vary from those that are developed in other nations. Firms that are active in multiple national markets are likely to confront specific local problems in each market. Variations in user needs, manufacturing processes, or availability of materials may require adapting technology to local contexts or developing new technologies to solve local problems".

With their idiosyncratic histories and technological pursuits, a presence in multiple nations can raise a firm's awareness of the different areas of the knowledge landscape and thus provide a varied set of raw material for knowledge combinations. Recombinatory search for new innovations occurs only among the knowledge elements that a firm is aware of. By crossing geographic boundaries firms can obtain access to these variegated technological trajectories. A research presence in multiple nations also links firms to multiple regional networks of knowledge faster than market mechanisms do. Knowledge is often held by local engineers and the identification, and the transfer and combination with knowledge acquired from other local contexts, is often made through network connections between such individuals (Ahuja and Katila, 2004).

A lead in "high technology" industries that may stem from investments in higher education and in research and development, not necessarily basic science per se (Nelson and Wright, 1992). Support for the purpose of enhancing awareness of what is going on in the world of science and technology, may be as valuable or even more valuable as generating new knowledge for the first time "in the universe" (Brooks, 1994). Although countries typically have scientific competencies across the broad range of research fields, they develop fields of relative strength and weakness, strongly influenced by the nature of the societal and technological problems to be solved (Pavitt, 1998).

Innovation through science and technology: Brooks (1994) gives a representative allocation of effort that goes into the introduction of a new product: "1) conception, primarily knowledge generation (research, advanced development, basic invention) $5-10 \%$; 2) product design and engineering, 10-20\%; 3 ) getting ready for manufacturing (lay-out, tooling, process design), 40-60\%; 4) manufacturing start-up, debugging production, 5-15\%; 5) marketing start-up, probing the market, 10-20\%".

Faulkner (1994) classifies the knowledge used in innovation as: "1) knowledge relating to the natural world, 2) knowledge related to design practice, 3) knowledge related to experimental R \& D, 4) knowledge related to the final product, 5) knowledge related to knowledge." The dimensions of the distinctions in the knowledge are: 1) understanding - information - skill, 2) tacit - articulated, 3) complex - simple, 4) local universal, 5) specific/ contingent - general/ metalevel. Jensen et al (2007) build on the distinction of knowledge as: 1) know what, 2) know why, 3) know how, 4) know who. They note that the types of knowledge would be learnt through different ways and channels. The types of knowledge are extended to innovation, in terms of the role of science and technology, and based on the mode of learning.

Rosenberg and Nelson (1994) note the difference between applied science and engineering, and point to the distinct roles of research and design as part of research and design (R\&D). Hong (1999) notes that scientific facts are inseparably linked with technological artefacts. Science represents a high theory and technology represents practical know-how, and the mediation takes place as the transfer of information from high to low (Hong, 1999). Lee et al (2016) note science acts as exploratory action in R\&D, while technology aims at an effective recombination of existing knowledge and its practical improvement. Technology is needed 
not only when establishing and reviewing alternatives to reach a certain R\&D goal, but also when forecasting possible problems and solving them during the innovation process.

Faulkner (1994) raises the ease of transfer and tradability of knowledge. The treatment of science as an exogenous source of technological enrichment obscures an important reality. Ahuja and Katila, (2004) state that "scientific developments do not naturally and costlessly sweep across a sector and enrich the search efforts of all firms in the same manner. Just as firms need to search across the technological landscape, they need to actively monitor and exploit scientific developments". Radical new scientific breakthroughs in knowledge are rarely a sufficient basis for a new product artefact; rather its development depends on the development of complementary fields of knowledge. Firms are becoming increasingly multi-technology based, incorporating a growing number of fields of knowledge as part of problem-solving (Pavitt, 1998). Nelson and Wright (1992) note that there is nothing simple about the processes through which firms come to adopt and learn to control technologies that have been in use elsewhere for some time. In science-based technologies the skills and experience needed to advance a technology include much more than can be acquired simply by working with that technology and learning from experience.

Freeman (1994) note that technical knowledge can seldom be obtained 'off the shelf and that it almost always requires processing and modification to be used effectively. Without this assimilation and improvement rather inefficient results are likely to follow. A particularly important aspect of knowledge accumulation is skill formation within firms as the combined result of formal training processes and learning by doing, using and interacting. Knowledge must be reinforced. According to Pavitt (1998), technology knowledge is accumulated through trial and error. Tacit (non-codifiable) knowledge is of central importance in technology learning processes, in deciding which component of the system to change, in interpreting the consequences of change, and in deciding what to do next. The capacity to understand and solve complex problems depends on an increasing range and combination of fields of technical knowledge. A significant proportion of the knowledge required in technological innovation is tacit or embedded in people, not codified or written down, and not communicable (at least at present) except by people working side-by-side (Brooks, 1994).

Nelson and Wright (1992) note that, to a considerable extent technical advance is local and incremental, building from and improving on prevailing practice. The knowledge useful for advancing technology includes, prominently, experience with the existing technology so as to be aware of its strengths and weaknesses, and to know how it actually works. Thus those at the forefront of the technology are in the best position to further advance it. Sustained technological advance is not the result of one person or firm pushing things ahead, but involved many interacting people and firms. One learned from another's invention and went a step further. In short, technological progress is a network phenomenon replete with network externalities related to path-dependence - dependence of successive developments on prior events, and a tendency for particular systems to become locked in beyond a certain point.

Freeman (1994) note that firms develop technical learning both from their own experience of design, development, production and marketing, and external sources of information, knowledge and advice: contemporary and future users of an innovation; other organisations (universities, government laboratories and agencies, consultants, licensors, licensees, joint ventures); and competitors (informal contacts and reverse engineering). Faulkner (1994) examines the knowledge used during innovation, and note that a majority thereof derives from in-house effort and expertise, the remainder from external sources. R\&D activities of course require a synthesis of the diverse contributions from both internal and external sources. Tacit skills, largely acquired on the job, make a greater contribution to innovation, than does formal knowledge, acquired from literature and education. About half of all knowledge from internal sources are collectively generated, and the rest is personal - already known to the researcher as a result of previous education and experience. Primary scientific research contribute to procedures and skills used in $R \& D$, and with experimentation. Scientific research mostly contribute to the top layer - initial steps - of R\&D: scanning the research frontier and underpinning knowledge. Internal sources do not contribute to theory, as much as scientific research.

According to Faulkner (1994), the reasons why internal knowledge is dominant are: Companies need to appropriate technology related to specific atrifacts, in order to extract rent and sustain themselves. Companies need local expertise to make sense of exploit external knowledge. Technological development is cumulative in nature, and manifests path dependence - one development suggests another. Knowledge acquisition and generation are also cumulative at the level of the firm, because learning is involved. Innovation requires specific knowledge, rather than general knowledge. Knowledge flow in the supply chain help to explain the involvement of outside companies.

Rosenberg and Nelson (1994) differentiate between breakthrough and incremental inventions. A major part of improvement is often in design, usually done in an engineering department and often not counted as R\&D despite the fact that it involves comparable activities. Many small firms engage in inventing, design, and 
development work without a formal R\&D department and often without reporting any R\&D (Nelson and Wright, 1992). Particularly when differentiating between incremental and radical innovation, the great majority of innovations do not come from formal R\&D. Formal R\&D play a different role in terms of incremental versus radical innovation: when one moves away from improvements in production to entirely new products and processes, then more formal inputs from the science-technology system are usually needed (Freeman, 1994). In the early stages of a truly radical innovation, scientific and technological inputs are likely to be prominent, even if they do not provide the original impulse (Freeman, 1994). By definition, any radical innovation involves some change in the organisation of production and markets. Organisational and institutional innovations are thus inextricably associated with technical innovations. They are also often related to changes in infrastructure (Freeman, 1994).

Keller (2008) notes the concepts of technology push and society pull in the context of technology. New technologies seldom can be seen at the outset even by those best equipped to understand their potential except as supplements to existing technologies and the existing systems of which they are a part (Adams, 1997). Supply push innovation may eventually find markets, even if none are initially anticipated (Freeman, 1994). The exploration of a new field of science is deliberately undertaken with a general anticipation that it has a high likelihood of leading to useful applications, though there is no specific end-product in mind Brooks (1994). More integrated views now prevail with regards to supply push versus demand pull - both supply push and demand pull can prevail during different stages of the innovation process or cycle. Cyclical phenomena exist in the growth of industries and technologies (Freeman, 1994).

Innovation varies by industry, degree of novelty and cost, technology, type (product, process, organizational, system) (Freeman, 1994). Industry types tend to show different patterns of external relationship to sources of knowledge, of in-house scientific and technical activities, of diversification behaviour, of industrial structure and of skill formation are highlighted (Freeman, 1994). Even though company size may impact on innovation capability, smaller firms also innovate and concentration and deconcentration usually takes place (Freeman, 1994). Rip (1992) notes some changes in the structure of the science-technology complex are: the emergence of combined technologies, technological development becoming increasingly simulated with software, rather than evaluated with hardware; technology processes becoming more strategic - choices are explored, rather than technical effects produced.

Convergence: Lee et al (2016) note the boundaries of industries, markets, and knowledge such as science and technology are gradually blurred. Many technologies became more like sciences than before: it is noteworthy that patents in certain industries tend to cite scientific literature to a far greater extent than do patents in certain other fields (Nelson and Wright, 1992). In methods, training, major features of their underlying theoretical frameworks, and even in the spheres of daily activity of individuals, science and technology have been more and more involved in a growing convergence and overlap (Adams, 1997). Taking a macro historic perspective, Hong (1999) shows how instruments (epistemological), socio-spatial (public meeting, universities, institutional research labs) and human (professionals that are interested in and contribute to both science and technology) boundary objects have help to blur the separation between science and technology.

Nelson and Wright (1992) note that truly international networks involve highly trained scientists and engineers, employed in universities and in industry, undertaking significant R\&D efforts. The technologies emerging from such networks no longer have geographic roots, because horizons have become global, and because material resource inputs more generally have declined in importance, relative to processing. Even though social capabilities are still national, commodity and resource trade, business and finance, and technological communities, have all become increasingly transnational rather than national. The convergence model looks more and more plausible, because of the internationalization of trade, business, and generic technology and the growing commonality of the economic environments of firms in different nations.

Lee et al (2016) note that, in order to archive impactful innovation, it is important to understand the combined effects of science and technology, referred to as the convergence of science and technology, as well as the individual effects of science and technology. Convergence is defined as, rather than solely depend on particular fields or knowledge sources, combining different knowledge from different or interdisciplinary fields or sources such as science and technology to create innovation which contains not only the integrated value but also synergies of the combined knowledge. Innovation is a process that combines knowledge with new ideas in a creative way from the knowledge side. Science assists in solving difficulties in the invention process and, as a result, positively influences innovation. Incorporating scientific knowledge into the research process occurs during the early stages of convergence and is the precedence of technological and industrial convergence. Convergence at the knowledge level is an important prerequisite for conceptualizing new innovation (Lee et al, 2016). 
By converging science and technology as two distinguished knowledge sources, new paradigms can spread. Especially, during the invention process, inventors can be inspired and stimulated by the convergence between cross-sources of knowledge. As science proposes fundamental ideas and aids in finding effective methods for problem solving with a technological aim, its utilizations permit the occurrence of an efficient innovation process when companies establish new products or adapt new technologies. Moreover, technological knowledge is beneficial in understanding technological trends and market needs while basic science contributes to the development of solutions that address these needs and requirements. Based on this idea, engineers and scientists' collaboration in R\&D is complementary, maximizing the convergence synergy. Due to the tacit aspects of scientific knowledge, knowledge spill over by nearby researchers with regard to solving technological problems through scientific domains would contribute to convergence effects. Factors that impact convergence are: 1) knowledge management and organizational capacity to handle knowledge, 2) knowledge spill-over from tacit knowledge in the form of human resources (through mobility and communication), and 3) the maturity (accessibility and codifiability) of knowledge (Lee et al, 2016).

\section{Paradigms, trajectories and search paths}

Freeman (1994) notes the analogy between scientific and technological paradigms: Technologies have natural trajectories of their own which enable designers, engineers, managers and entrepreneurs to visualise likely future paths of development and growth. Rip (1992) notes the pattern of autonomous development of technical domains, which resemble scientific domains. A local technical model can be problematized because it fails to solve design problems, and this may lead to local excursions into meta-modelling, involving scientific research and/ or learning. Ideas for new artifacts and designs may emerge out of local meta-modelling research.

Diffusion of innovation - a changing product in a changing environment - refers to the fact that new products and processes are usually changed considerably during the diffusion process, and further innovation make take place during the diffusion process. Innovation involves initially an increase in diversity - an extension of the range of products, processes and services. In the early stages of diffusion, this diversity will usually increase. This diversity may be further increased by the divergence of national markets, production and technology systems. Since radical innovations also involve organisational and other institutional innovations there is scope for very considerable variety (Freeman, 1994). Diffusion is both a supply-side and demand-side phenomenon. Diffusion has a systems aspect: most innovations are not discrete events or isolated products but form part of a technology system. Diffusion is dependent on skill intensity, learning and training, and managerial and organisational innovations in such areas as labour relations, incentives, hierarchical managerial structures, communication systems within and between firms, stock control systems and so forth (Freeman, 1994).

Beukel et al (2014) conceptualize search as an expression of the distinct knowledge sources exploited for problem solving. Search differ across science and technology - search in science is aimed at understanding phenomena (why an effect appears), while search in technologies is directed to exploiting existing solutions in further innovations (how an effect appears). Organizational learning utilize both explorative and exploitative search. They highlight the cognitive direction of search and problem solving in R\&D. Cognitive maps refer to the constructs allowing people to perceive and interpret the current situation in relation to its environment, in their search for suggestions of which orientation to follow. Search in the forward looking approach concerns linkages between choice of action and subsequent impact. This type of problem solving centers on the development of hypotheses related to identification of potential causal relationships. Search in the backward looking approach is exploitative and uses existing knowledge.

Rip (1992) notes the complexity of the world of science and technology can be addressed from the perspective that the practices of science as well as technology consist of search processes and institutionalized activities. Even while their historical forms are separate, there may be no essential difference. Science and technology differ as institutions, and their products and contexts differ. Search processes are structured by heuristics - rules that do not guarantee but promise some success in problem solving. The heuristics are shared and embedded in organizational contexts and/ or practitioners' communities. The products of the search processes are exposed to assessment and selective use by others. Two processes are at work: articulation of (a matrix of) expectations and incorporation of new information and assessments; and sedimentation - the emergence of shared and stabilized repertoire of expectations, on which actors can draw as a resource. Institutions relevant for technology and science emerge and function as a response to the activities of anticipation on selection, as an attempt to reduce uncertainty and create stability in the environment. Social loci house such heuristics, and create a dynamic of its own, further advancing the search process and its underlying processes. This relates to and corresponds with paradigms and trajectories. A paradigm may be at different levels of maturity. 
Ahuja and Katila (2004) note that, central to the resource-based view of the firm is the idea that firms differ in their resource positions, and that such resource heterogeneity is a source of performance differences across firms. Firms respond to idiosyncratic problems and opportunities facing them by embarking on new search paths. The creation of such new paths is the cornerstone of resource heterogeneity. Inertia and momentum sustain change along pre-existing paths (path-deepening search). Two types of idiosyncratic situations - technological exhaustion and market expansion - lead to path-creating search. Firms that are inventing in arenas where the technology is well exploited are driven to search scientific knowledge to acquire fresh raw material (science search). Similarly, firms that are entering new international product markets are driven to expand international research to address local opportunities and problems (geography search). Two circumstances exist through which new search paths for resources are created. The first circumstance is the unexpected problems that arise during local search efforts in the form of puzzles or boundary conditions. The second is the unforeseen opportunities that arise from unexpected situations. Idiosyncratic incidents, such as problems or surprises, can change search patterns of individuals and groups.

Social aspect: Keller (2008) notes the systemic perspective: science and technology are themselves embedded in political, economic, social, and cultural systems that affect their directions, success, and impact. Great value is seen in paying attention to technology outcomes that society may need or want. Before a new techno-economic paradigm can generate a new wave of world-wide economic growth, there is a period of adaptation of the socio-institutional framework (Freeman, 1994).

\subsubsection{Uncertainty}

Courtney et al (1997) list four levels of uncertainty organizations face: 1) a clear enough future - a single forecast precise enough to determine strategy; 2) alternative futures - a few discrete outcomes that define the future; 3 ) a range of futures - a range of possible outcomes, but no natural scenarios; 4) true ambiguity no basis to forecast the future. Mullins and Forlani (2005) argue that, when it comes to new venture decision making, the likelihood of loss (sinking or missing the boat) and the magnitude of loss (the size of the boat sunk or missed) capture the essence of entrepreneurial risk. The likelihood of loss entails either the potential to act too quickly on an unsubstantiated opportunity, thus "sinking the boat," or the potential to wait too long before acting, thus "missing the boat." Sinking the boat is defined as the likelihood that a new venture will fail to reach satisfactory sales; missing the boat is defined as the likelihood that a very attractive opportunity will be overlooked, dismissed, or lost because of competitor preemption or changing markets. Ahuja and Katila (2004) note the risk associated with searching new paths for opportunity and solutions.

Based on this, the risk associated with a new opportunity can be classified in terms of the risk associated with the end or outcome of the venture, the risk prior to having produced a basic prototype, and the risk post having a basic prototype. The risk prior to a basic prototype pertains to sourcing a feasible opportunity, and developing - stabilizing - it into a basic prototype as solution. The risk post the basic prototype pertains more to further improving the solution, and commercializing the product. Reaching a basic prototype is seen as an important landmark of the opportunity, especially in cases where the technology underlying the value offering was improved, as this point accompanies a basic stabilization or crystallization of the technology. When a basic prototype is obtained, the technology mix is unlikely significantly changed anymore, even though the technology self may still be improved. Marketing, operations, and management functions and planning should also be clearer and easier post prototype.

\subsection{The Environment of Value Creation}

To delineate the environment of value creation, the principal ontological matter (Earle, 1992) physical, non-physical, and abstract objects - are incorporated. The primary fields in philosophy are also used. As shown in Figure 1, this results in a definition of the environment in terms of fundamental philosophical concepts - physical objects and the physical environment, influenced by more abstract concepts like knowledge, and assimilation along the lines of religion, economic, political, ethical, and social norms.

This should also be considered along space and time - even though the broad reference is the same, the depiction would be conditional on time and location. Organizations need to know that their offering would be sustainable for a duration of time, to recuperate the costs involved.

This is similar to contemporary depictions of the organization's environment, like PESTEL (Yüksel, 2012). The main difference is seen as a more basic justification of the fields included, with a greater emphasis on knowledge, rather than merely technology, equally influencing the other fields.

According to figure 1 , customers and organizations are separated through the market. A key implication of this is that, even if the organization adequately understands the customer and his needs, and even if the organization is able to produce a value offering of sufficient quality to address the identified need, 
such that the value offering of the organization stands out, it is not guaranteed that the organization may reach the customer. A key factor in this regard may be competitors, and their actions, essentially blocking the organization.

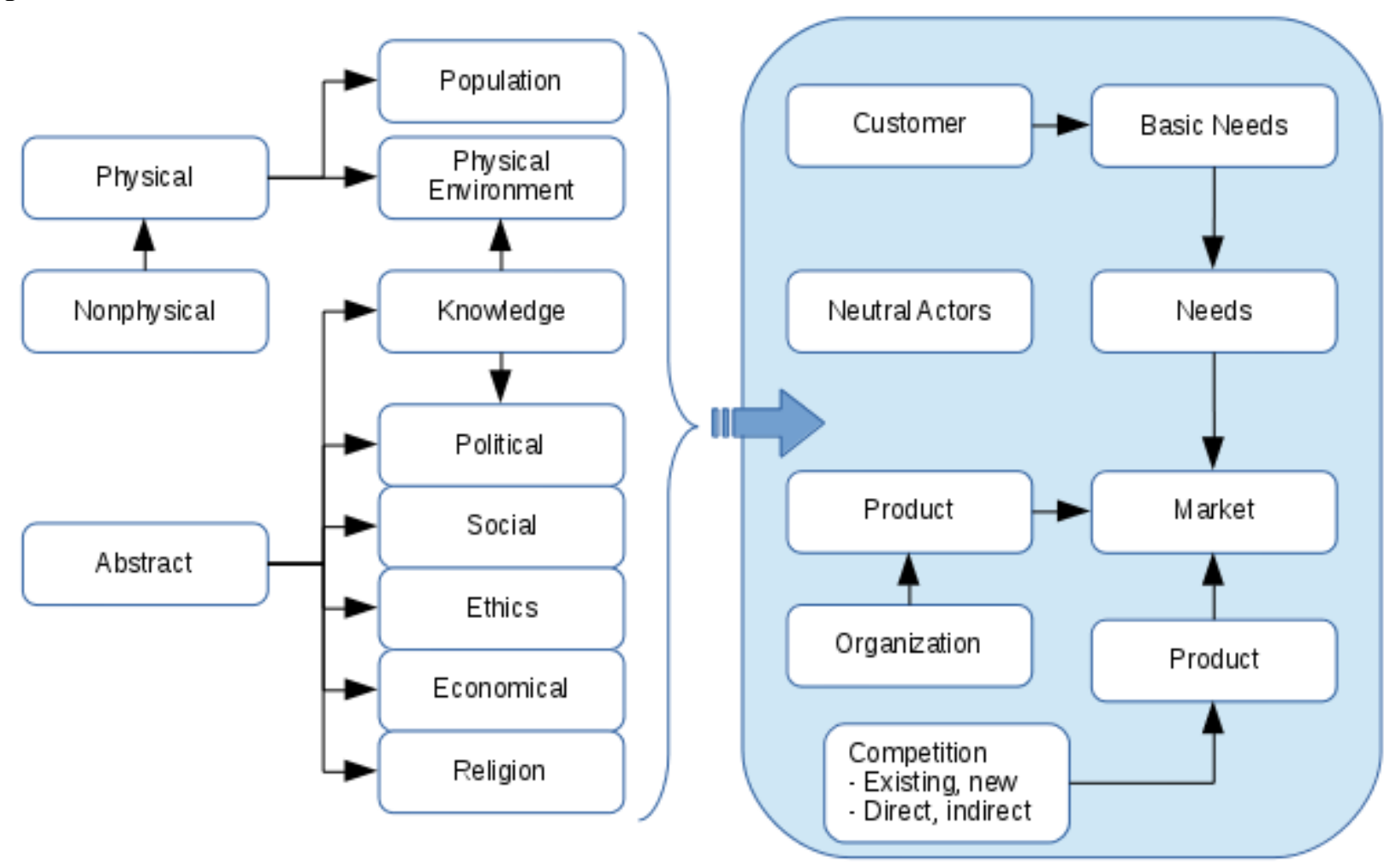

Figure 1: The environment of value creation

\subsection{Conclusion}

From the above, a number of conclusions and propositions are made:

In order to create value, it is clear that adequate knowledge is required about customers needs (also stemming from their basic needs), ways to satisfy such needs, the value offerings of direct, indirect, existing, and new competitors, and potential changes in the customer and business environment.

Basic needs are regarded as generally stable - even though basic needs may vary in terms of magnitude across different demographics, segments, and so forth, it is unlikely that basic needs as classes themselves vary regularly, if at all. The satisfaction of basic needs likely follows a continuum - basic needs are unlikely entirely satisfied, or entirely unsatisfied. The language - concepts and constructs - of customer perceived value and satisfaction (attributes, benefits, goals, purpose, utility, equity, expectation, affection) support the argument that basic needs underlie customer perceived value and satisfaction, and that the predominant portion of consumption is purposeful and directed. Basic needs help to explain the goals and purposes of customers. Basic needs also relate to value offerings of organizations. Value offerings are equally purposeful: value offerings are directed - intentionally or unknowingly - at basic needs; even supply side technology push amidst new science has broad expectations in terms of benefits.

Given that customers form expectations regarding the promised or received value of value offerings, it is elementary to conceive that customers will extend their perceptions of value to new value offerings entering a market, or targeted at a specific need. Thus, like existing value offerings, proposed - planned, new, future - value offerings are also grounded in customer perceived value. Proposed value offerings never reach customers in isolation of existing value offerings.

Thus, value is created if and only if customer perceived value improves, and the uniqueness of value created relate to (the improvement in) customer perceived value. A value offering with inferior customer perceived value assessment, relative to the average customer perceived value assessment, would unlikely be successful. Also, a value offering that matches the average customer perceived value rating would merely constitute a transfer of value. Uniqueness of value created is likely measured along a continuum. Because value offerings are grounded, and because value creation always accompany a replacement of existing value offerings by a new value offering, both from a demand side and supply side perspective, value creation is not regarded as entirely unique from a demand side or supply side perspective. 
Because they resemble similar knowledge properties, organization and management are also seen as forms of technology. Also, science is seen to incorporate both natural science and social sciences. Because science must be codified to technology, value creation cannot stem from science, although it can be inspired by it. Then, value creation through improved customer perceived value may be brought about by a change in the technology underlying the value offering, relative to that of existing value offerings, or by improved institutional, organizational or management methods - management technology. In this sense, transferring existing solutions to new or unique locations are also seen as creating value, as long as customer perceived value is improved for a segment of customers. To the extent that this has not been negated, customer perceived value is local to context, and not globally the same. It also implies that existing value offerings are minimally optimal, given applied technology, and organization - at present better technology or organization can not be suggested and implemented to improve the existing value offering (without an innovation intervention).

Given that it builds on existing science and technology, new technology is constrained by existing science and technology. As mentioned, existing science must be codified to technology. Technology emerges and is developed, and must be advanced through learning. Technology can be combined and recombined; science may aid this. Science and technology can be imported with cost (learning), and technology can be exported with benefit. The sector or market the technology is exported to, determines the extent of additional learning required to render it successful. Radically new technology would need to include new science, or a radical combination or recombination of existing technology, to truly differentiate it from existing technology. Properly devised at customer perceived value, radically new technology has greater chance of value creation, but is also more risky than marginally new technology.

In all instances, new value creation requires entry knowledge. This will constitute technological knowledge, and may indirectly constitute scientific knowledge. It is taken that it is not possible to improve on the customer perceived value of existing value offerings without a comparable effort of understanding of the technology used to implement them - even if the new value offering does not directly build on the existing technology used to date, and breaks from it, it is taken that the effort of understanding or learning required would not be less, but the same or more. Thus, the extent of entry knowledge required is proportional to the knowledge embedded in existing value offerings.

In all instances, new value creation also requires new knowledge. In the cases of a transfer of existing solutions, a degree of technical knowledge as learning is still required. In this case, the extent thereof is proportional to the knowledge embedded in the existing value offering, and the location it is transferred to. In the case that the solution itself is improved, the extent of the creation of new knowledge is proportional to the existing knowledge, and the amount of new learning - the uniqueness of the science and technology to be incorporated.

Value creation opportunity may be identified supply side or demand side - the organization may know of technological avenues it wishes to pursue further, or the organization may attempt to revisit and revise the satisfaction of certain (basic) customer needs, without necessarily already having decided the means to do so. In essence, opportunity may be recognized, or sought. Knowledge pertaining to opportunity exists with individuals, groups, in artifacts, or in literature, but may not be automatically recognized as such. This knowledge is cognitively surfaced by: 1) collective, existing knowledge, 2) interaction, as well as 3) further inquiry or learning. Customer data on basic needs, customer perceived value, and customer satisfaction; technology data on scientific and technological knowledge; and corporate data on organization, management and environment, including direct and indirect competitors, and similar or global markets, are all possible sources.

Sourcing and identifying opportunities may be distinct in terms of incremental and radical opportunities, and then possibly difficulty or complexity of identification. When regarding the cognitive nature thereof, opportunity recognition and development utilize heuristics, analysis and other cognitive processes. Search paths may be embedded in scientific and technology paradigms and trajectories. Even though revealing, search processes and heuristics may expand beyond explorative and exploitative, and science-based or technology-based, and may include more detailed heuristics. Scientists, engineers/ technologists, and managers may all follow unique heuristics.

Value creation may essentially be institutionalized, given the quantity of entry knowledge and new knowledge, and thus resources, required - organizations may be better positioned than individuals. Yet individuals may carry unique perspectives that may enable value creation. This suggests a role to be played by both individuals and organizations, and better interaction between the two parties.

If the contribution of science to technology is over-emphasized, a greater commitment to technological development may help technology contribute more to science, restoring the balance. It still requires interaction and awareness between science and technology - academic institutions and industry. The interaction between 
science and technology may impact optimal levels of value creation. Still this requires some commitment by industry to relay pressing issues and may require alertness.

\section{Methodology}

To empirically examine the demand-side and supply side necessary conditions of value creation, semistructured interviews were conducted with entrepreneurs, and professionals employed in an innovation capacity. The interviewees have been directly involved with innovation and entrepreneurship, with appropriate level of experience. Eleven interviews were conducted. The interviewees were asked twenty-five questions.

Table 1. Interview instrument

\begin{tabular}{|c|c|c|}
\hline 1 & $\begin{array}{l}\text { In your opinion, what are the necessary conditions of value creation - } \\
\text { what is required to create value? }\end{array}$ & $\begin{array}{l}\text { What do innovators see as the } \\
\text { necessary conditions of value } \\
\text { creation? }\end{array}$ \\
\hline 2.1 & $\begin{array}{l}\text { Do you think customers' needs can be categorized in broad or basic } \\
\text { classes? Do you think such basic classes would be stable, or fluctuating? }\end{array}$ & \multirow{3}{*}{$\begin{array}{l}\text { How do innovators understand, } \\
\text { perceive, think of, and approach } \\
\text { customers' needs and basic needs? }\end{array}$} \\
\hline 2.2 & $\begin{array}{l}\text { Are customers purposeful? Do you think customers reference such basic } \\
\text { classes when they review value offerings? Would it help to explain their } \\
\text { behaviour or actions? }\end{array}$ & \\
\hline 2.3 & $\begin{array}{l}\text { Do you reference such basic classes when evaluating your ideas? If so, } \\
\text { to what extent? }\end{array}$ & \\
\hline 3.1 & How do customers value, evaluate or rate value offerings? & \multirow{5}{*}{$\begin{array}{l}\text { How do innovators perceive and } \\
\text { approach customer perceived value, } \\
\text { and do they relate it to current value } \\
\text { offerings, and opportunity - their } \\
\text { offerings? }\end{array}$} \\
\hline 3.2 & $\begin{array}{l}\text { Do you think customers reference new value offerings against existing } \\
\text { value offerings? And is this a dominant or crucial factor? }\end{array}$ & \\
\hline 3.3 & $\begin{array}{l}\text { How do you attempt to devise a value offering that is different from } \\
\text { others? What are the deciding factors that cause customers to consider } \\
\text { your value offering, above that of others? }\end{array}$ & \\
\hline 3.4 & How do you gauge the uniqueness of your value offering? & \\
\hline 3.5 & $\begin{array}{l}\text { Do you think customers perception of value - both of existing value } \\
\text { offerings, and your value offering - can be used as an evaluation criterion } \\
\text { during evaluation of innovation projects, throughout the process of } \\
\text { innovation? }\end{array}$ & \\
\hline 4.1 & $\begin{array}{l}\text { Is there a knowledge - scientific, technical, or management - or } \\
\text { information entry barrier to innovation? That is, a minimum level of } \\
\text { knowledge or information you need to possess in order to innovate? }\end{array}$ & \multirow[t]{3}{*}{$\begin{array}{l}\text { What entry knowledge do innovators } \\
\text { perceive they need to possess? }\end{array}$} \\
\hline 4.2 & $\begin{array}{l}\text { Does it in any way relate to knowledge and information already } \\
\text { embedded in existing value offerings? If so, how? }\end{array}$ & \\
\hline 4.3 & $\begin{array}{l}\text { Is it difficult to overcome this knowledge entry barrier? Do you easily } \\
\text { overcome this barrier? }\end{array}$ & \\
\hline 5.1 & $\begin{array}{l}\text { Do you absolutely need to create knowledge - scientific, technical, } \\
\text { management - or information to innovate? }\end{array}$ & \multirow{4}{*}{$\begin{array}{l}\text { How do innovators perceive the } \\
\text { extent of knowledge they need to } \\
\text { create? And how do they source it? }\end{array}$} \\
\hline 5.2 & $\begin{array}{l}\text { Does it in any way relate to knowledge and information already } \\
\text { embedded in existing value offerings? If so, how? }\end{array}$ & \\
\hline 5.3 & $\begin{array}{l}\text { Is it in any way difficult to produce this knowledge or information? How } \\
\text { do you source or surface the knowledge or information? }\end{array}$ & \\
\hline 5.4 & $\begin{array}{l}\text { What is the scope of the knowledge or information you utilize to } \\
\text { innovate? Do you incorporate diverse sources of knowledge or } \\
\text { information, and do you extend far from the areas or fields known to } \\
\text { you? Do you keep with related fields, or do you consider unrelated } \\
\text { fields? }\end{array}$ & \\
\hline 6.1 & $\begin{array}{l}\text { When searching for and identifying opportunities, do you actively make } \\
\text { an attempt to search for opportunities, or do the opportunities rather } \\
\text { register with you? In the case of the former, how do you search for }\end{array}$ & $\begin{array}{l}\text { Opportunity method, sources, and } \\
\text { knowledge }\end{array}$ \\
\hline
\end{tabular}




\begin{tabular}{|c|c|c|}
\hline & opportunities? & \\
\hline 6.2 & $\begin{array}{l}\text { In your opinion, is it more difficult to source or identify opportunities, or } \\
\text { to develop them - at least to a basic concept or prototype? Kindly } \\
\text { motivate. }\end{array}$ & \\
\hline 6.3 & $\begin{array}{l}\text { It is possible to know or discern in advance that an opportunity may only } \\
\text { be incremental, or that the opportunity may indeed be radical in terms of } \\
\text { outcome? }\end{array}$ & \\
\hline 6.4 & $\begin{array}{l}\text { Is it more difficult to source or identify radical opportunities than } \\
\text { incremental opportunities? }\end{array}$ & \\
\hline 6.5 & $\begin{array}{l}\text { When searching for and identifying opportunities, what are the sources } \\
\text { of knowledge or information you reference? What are some of the things } \\
\text { you look at or look into? }\end{array}$ & \\
\hline 6.6 & $\begin{array}{l}\text { Is it in any way difficult to source the knowledge or information? How } \\
\text { do you source or surface the knowledge or information? }\end{array}$ & \\
\hline 6.7 & $\begin{array}{l}\text { Do you ever consider management or business science, or management } \\
\text { or business technology as a viable source of knowledge or technology to } \\
\text { incorporate into innovation - as a viable source of opportunity? }\end{array}$ & \\
\hline 7.1 & $\begin{array}{l}\text { Do you think knowledge is important for innovation? If so, what is the } \\
\text { role of the innovator or entrepreneur, and what are the opportunities for } \\
\text { innovators and entrepreneurs? }\end{array}$ & \multirow[t]{2}{*}{$\begin{array}{l}\text { The relationship between knowledge } \\
\text { and opportunity }\end{array}$} \\
\hline 7.2 & $\begin{array}{l}\text { Do you think educational institutions can help or play a greater role in } \\
\text { this regard? Can industry, educational institutions, and innovators or } \\
\text { entrepreneurs better cooperate? }\end{array}$ & \\
\hline
\end{tabular}

During the interviews, the following definitions and conventions were used:

i. A value offering is a product or service.

ii. Innovation and thus the customers may be external or internal to the organization, and may be business to business (B2B) or business to customer (B2C).

iii. Innovators equally imply entrepreneurs. Both innovators and entrepreneurs are seen to innovate, in that the attributes of value creation are the same.

iv. Knowledge incorporates scientific, technological, and management knowledge. Technological knowledge includes know-how and experience. Scientific knowledge incorporates both natural sciences, and social sciences.

\section{Analysis}

Below, the transcribed interviews.

Q1.1: In your opinion, what are the necessary conditions of value creation - what is required to create value?

To under-promise and over-deliver frequently surfaced. Value was largely seen as customer-centric dependent on the customer. What a business sees as value may differ from what clients see as value. Value differs from client to client; it may not necessarily be price or quality per se. Consequently, it was seen as important to understand the customer and his circumstances, what he expects, and to know what the customer wants or needs. The innovator must learn to better understand the client, and what he sees as value. In essence, a need must be satisfied, whether it is a real need or a perceived need. The innovator may also need to understand the psychology of the customer.

Value creation is associated with benefit and value contribution. A customer buys a product, because he gets what he wants. The value contribution must be justifiable. Thus, it relates to the extent that the contribution can be removed, and the result or outcome is still (no longer) the same. There is a clear distinction between the amount of benefit created, and the amount of benefit the customer experiences and enjoys. Value relies on having a perceived value that is much higher than the actual cost of manufacturing the product, such that customers will be willing to pay the premium. Value comes from the company's ability to take advantage of a problem - coming up with a solution that solves a problem. A problem is defined as where an individual is, and he needs or wants to be. The value created assists the targeted customer to bridge the gap between where they are and where they need or want to be. The attribute aspect of value is mentioned - what you pay, 
and what you get.

Value creation requires following and understanding the competitive landscape - industry trends, the competition, and so forth. Knowing what is going on in the market and investigating what others are and are not doing, in order to find a niche.

Value creation also requires meeting the expected value - ensuring to deliver on whatever the expectation is. The distinction between perceived value, offered value, and actual or realized value is made. The notion of missing value is noted. It may be small things added to the product that increases the perceived value and realized value. Some things may not cost much - like being reliable - but may equate into significant customer percieved or realized value, and may create unique selling propositions and competitive advantage. Related to missing value and expectations, the notion of non-verbal agreement was raised.

Value can also be created by increasing and improving the customer's experience, even if it means an experience outside of what the customer asked for or expected. Over and above physical proposition, subconscious elements are also seen as important. It is more than the service or product that is provided; it is equally about the experience that the person ends up with. Customer relationships and trust were also mentioned frequently. In general, building relationship and trust with the customer, living up to promises, being reliable, and being there for the customer. The way the customer is treated is important.

\section{Q 2.1: Do you think customers' needs can be categorized in broad or basic classes? Do you think} such basic classes would be stable, or fluctuating?

It is taken that needs can be classified according to various categories, and that is possible to come up with broad categories. Some saw basic needs as stable. Yet, the view in general is that customers may have basic or generic needs, and that it fluctuates. What the customer wants the world to think who he is definetely changes over time. It is influenced by factors such as circumstances, psyche, age, life stage, the life and wealth pyramid, personality, aspiration, and the development of worlds (technology, social, economic, etc). It also depends on how customers manage, address and deal with those specific needs they have identified. To an extent, it may not be reversible, and may be semi-permanent. It is also possible to digress. Furthermore, it is viewed that some needs can exist as different versions at different levels. While the customer addresses a need, different versions of that same need are carried to higher levels.

\section{Q 2.2: Are customers purposeful? Do you think customers reference such basic classes when they} review value offerings? Would it help to explain their behaviour or actions?

The responses were divided. A number thought that, for major purchases and normal needs, customers behave rationally. Others noted that, even people who believe they are rational and that they do evaluate their purchases rationally, do not make decisions with true rational application. Also, there is a window during which it is possible to persuade the customer and change his mind. The customer can indeed be influenced and manipulated to buy things he did not necessarily want. Also, customers may not really know what they want, and may make purchases out of pressure. What customers want and what they really need may differ too.

Purposefulness or impulsiveness can equally depend on factors like life-stage. The notion justified impulsiveness was also raised - having credible reason for engaging in a transaction that would generally be classified as impulsive. Another factor was whether the customer purchases for himself, or whether he acts as an agent or representative. Business to business (B2B) may differ from business to customer (B2C) in that the decision-making process differs.

Customers may consider what they need, and the benefit they get from the product. At the same time, customers may not necessarily be aware that they are making these type of comparisons, although it can be discerned though research. Customers may not always see the value or identify the value being offered and delivered, and may only see a product. Although they expect certain things, they do not necessarily go into great detail to categorize it. At the same time, there is significant purposefulness on the side of companies.

\section{$Q$ 2.3: Do you reference such basic classes when evaluating your ideas? If so, to what extent?}

Some only expressed a primary objective of evaluating and addressing immediate customer needs, and creating emotional connection and association. Companies are purposeful, and may reference basic needs in some capacity when devising products. Basic needs do not form the dominant evaluation criterion, and are utilized with other criteria such as economics, product benefits, customer perceptions, customer satisfaction, and trends. Basic needs can be used to determine how relevant and thus how successful a product would be. It can help to identify opportunities, target products, and identify threats. Basic needs may be a supplier construct, rather than a customer construct - it may be more useful to the supplier than the customer. 


\section{Q 3.1: How do customers value, evaluate or rate value offerings?}

That customers vote with their money was frequently mentioned. Whether they are willing to spend their money and time, and associate with your product, and recommend your product, was also seen as a prominent criterion. Price, needs, expectation, functionality, quality, benefit, satisfaction, trust and integrity, relationship, reputation (including referral and clout), prestige, and support were the other factors mentioned. In general, it is expressed as having a quality product at a good price.

It is noted that customers may not always really perceive the true value offering - the value designed into a product. Also, customers may purchase the product that satisfy their expectations, including quality and price, without necessarily considering other offerings. There is a cost involved in comparing different offerings too. Customers may only switch to a different product when they are no longer satisfied with a product, their expectations are no longer met, or the relationship is damaged.

\section{Q 3.2: Do you think customers reference new value offerings against existing value offerings? And} is this a dominant or crucial factor?

New products may need to compete with existing products - the new products are compared with existing products. At the same time, new products may equally disrupt the market and status quo - the new product has a significant improvement in value offering, such that it is hardly compared with existing products. A unique value offering would also mean the value offering does not exist and cannot be obtained through other products, such that existing products become less relevant. At the same time, the customer may not necessarily recognize the value built into the product, which is equivalent to not making any comparisons.

New products must take market share from existing products. Good reason must exist for customers to switch to or try a new product - the new product must be differentiated from existing products. The higher the cost, implication or risk to the customer, the more the customer will evaluate new products against existing products. It may take time for the new product to build up a reputation and following.

Customers may be open to suggestion. Factors like circumstances and situations may influence whether the customer is open to suggestion. Customers may fall into behavioural patterns too, and become familiar and attached or associated with products - show loyalty. On the long term, customers are a lot more open to introduction and interception, and there are techniques to interrupt the sales or purchase journey. Specific factors, like technology, contained in the value offering of the new product may also trigger the customer to strongly consider the new product. Specific factors, like sophistication, embedded in the value offering of existing products may also entrench customers. These customers consider the switching cost.

$Q$ 3.3: How do you attempt to devise a value offering that is different from others? What are the deciding factors that cause customers to consider your value offering, above that of others?

It is believed that customers are not too sophisticated in this regard. It is only necessary to provide value for money, and to ensure that products are sufficiently differentiated from competitors' products. Innovators tend to focus on i) understanding the customer's problem, such that it is a no-brainer for the customer to buy the product; ii) the quality, benefit, functionality, convenience and satisfaction the customer gets from the product, as well as the experience and association the customer has with the product; iii) ensuring the expectations of the customer are met; and iv) the desirability of the product. This can also realize through the competencies that the company invest in, build up and acquire.

Psychological factors, like first impressions, and signalling to the customer that he is being taken to heart, were also seen a relevant. In this regard, innovators focus on i) paying attention to relationships and building mutually-beneficial relationships, also to increase referrals; ii) building trust and reputation; and iii) engaging the customer in order to start building relationship with him.

Innovation by itself does not always win the market. Significant marketing and advertising may be required, as well as getting the customer in contact with the product.

\section{Q 3.4: How do you gauge the uniqueness of your value offering?}

The market provides clear feedback, and it is possible to determine whether the gap identified in the market is being filled adequately. Specific factors mentioned were price, quality, marketing and branding, competition, and relationships.

Customer feedback, including informal communication and talks with customers, after-sales service, and actual sales are all seen as forms of feedback. Other forms of customer-based feedback noted were whether the customer specifically asks for a brand, and for the innovator's brand, sales conversion (does the company get more customers), customer retention (does the company retain its customers), and whether the customer comes back. 
Attention is also given to the competition. Innovators try to ensure that there is enough differentiation between competitors' products and their products, and that competitors cannot offer what is being offered. They focus on building relationship with customers, so that customers deal with a person, not a product. This increases the service offered to the customer, and helps to differentiate from the competition.

Furthermore, effort is put into building up the brand, and what the brand stands for, changing the product and market mix, and evaluating whether customers listen to and respond to the signals sent to them.

\section{Q 3.5: Do you think customers perception of value - both of existing value offerings, and your value offering - can be used as an evaluation criterion during evaluation of innovation projects, throughout the process of innovation?}

The customer's perception of the value can be used only up to a point. And exactly how to do it is not that simple. The innovator must have an idea to take to the customer - he cannot approach the customer with nothing. It is not possible to get a customer perception until the customer is given something to have a perception about. The customer's perception may not always be completely formed, as long as the product is not completely developed. Ultimately, it is not clear how the customer is going to react in the end. The innovator can only hope that his research was substantial and that the identified need would be satisfied when the customer actually sees the final product for the first time. The innovator wants to know what the customer's impression is going to be, based on his existing experiences, even though he does not have the final product already to have an impression about it. The final blend of features, and the final offering, in totality, also have an impact, and the customer may be flippant about and renege on previous perceptions expressed. It may imply having to make certain predictions.

A key objective is to really determine the perception of the customer, what the variables they use are, and to align what the innovator deems as value and what the customer deems as value. Also, understanding what the customer values and understanding the incentives and needs of the customer. It may involve getting the customer on the same page - educating the customer and shaping his perceptions. The client must be read, and it requires a level of skill to be able to read the perception from the client. A lot of psychology is involved. The interaction and transfer of information may be complex, obscure and tacit.

Q 4.1: Is there a knowledge - scientific, technical, or management - or information entry barrier to innovation? That is, a minimum level of knowledge or information you need to possess in order to innovate?

The results varied, yet with a common trend. The ability to innovate is seen as a general skill. The passion, interest, drive and desire to innovate is a primary starting point. Skills determine how far an idea can be taken, and the innovator may not have the technical know-how to address an opportunity. Yet, the innovator may be skilled in overcoming the knowledge barrier, and knowledge of how to get an idea going may be enough. He may be knowledgeable in acquiring and pulling the required skills together, buying in the technical skill, forming partnerships, or accessing and drawing from others to get an idea going. The knowledge and skill required for the opportunity can be bought or learnt.

The knowledge required is not necessarily limited to scientific or technical knowledge, but may also be business knowledge - understanding the industry, customers, competitors, and how to venture. Some knowledge regarding the particular industry, the existing products, and the expectations and satisfaction of customers of the particular market is required. The customer of that market must be understood, to be able to know how to innovate for them, and to be able to know what the customer would want if he knew it could exist. It is mentioned that innovation is about improving on the existing. The innovator will always need something to start off with. He can not innovate, if he does not think how things can be better and different. The previous processes used must be understood, in order to improve on them. This implies a certain knowledge of what already exists.

Having an idea is seen as different from implementing an idea. It is predominantly a lack of implementation that holds ideas back. A group of like-minded people with similar ideas and similar passion to solve issues can help with the implementation. Thus, the innovator can equally source the required skills through a group. It is also mentioned that innovation is not necessarily creating something new, but also applying what already exists to new problems. Hence, existing knowledge can be processed and combined in new ways just as well.

It may be specific to the opportunity identified, and the complexity involved. The existing product or market may be sophisticated, such that a significant amount of knowledge is required to be able to match the quality already offered. Also, products that are simple in one facet, may require something complex in other facets, to be able to compete. For example, a product that is simple to take to market, may require a more 
sophisticated customer experience. This sophistication can be seen as a barrier, because it may be necessary to produce or reproduce this level of sophistication.

\section{Q 4.2: Does it in any way relate to knowledge and information already embedded in existing value offerings? If so, how?}

It is seen to relate to existing levels of know-how, products, and the market. In many cases, the new is a development of what has gone before. The ability to innovate is seen as strongly related to existing knowledge of a product - a particular problem (market) must be understood, in order to be able to innovate it. However, a basic level of knowledge may suffice. Innovation may be thinking about something afresh. Still, a certain amount of background knowledge may be required. In some cases innovation requires re-learning - learning certain things already known to others. This implies a knowledge gate that cannot be circumvented. Even if the innovator buys in the skills, he is essentially pulling in existing knowledge. There are also valuable lessons in what did not work before. Products are complex systems of various processes and components, including customer experience and what the customer perceives as value. This entails a degree of background knowledge and understanding.

The view was frequently surfaced that it is not possible or no longer possible to make something $100 \%$ new.

Q4.3: Is it difficult to overcome this knowledge entry barrier? Do you easily overcome this barrier?

It is noted that people with zero organizational knowledge and zero established systems still manage to innovate. The innovator can make it his business to obtain the knowledge or information he needs. Also, he can buy in the skills and know-how he requires, but lacks.

Information is more readily available and cheaper, and markets move faster, and these are seen as enabling factors. Anything is possible through research, and everyone is free to learn. Yet, learning may be difficult, require time and carries a cost. Thus, a barrier in the form of learning and gaining the necessary experience and expertise may exist. Simply wrong mind-sets and poor psyche may be barriers too.

Lack of understanding and knowledge may be a barrier as well. A proper reference point is needed, otherwise innovation will not be possible. A conception of the customer and his needs is still required, and the customer, product and market must still be properly understood. Proper alignment with the needs of the customer is necessary. Also, customers may equally think that the value the innovator creates is common to the industry.

It may depend on the complexity of the products and processes involved. It may take a significant amount of time and resources to catch up with an industry, and the experience in the industry. Some of the knowledge required may be protected, and individuals that possess it may be reluctant to share it.

It may equally depend on the field of interest of the innovator. The innovator may bring to the table the skills he has, and can acquire the rest of the skills he does not have, but need. Yet, innovators may be restricted by the skills sets they have, and may be forced to stick to the knowledge base and skill set they have or feel comfortable with. Innovation can and should be benchmarked too to stir up innovation - seeing the quantity and quality of innovation coming out of other places (competitors, countries) may spur innovation.

\section{Q 5.1: Do you absolutely need to create knowledge - scientific, technical, management - or information to innovate?}

Basically, the innovator may only need an idea, or to identify a problem, to start with - he may not require knowledge for his idea. Innovation may be as simple as studying something. Innovation may also simply be the combination of ideas. The innovator builds on his experience and produces new experience. Innovation may mean taking an existing formula and adapting it to fit in a new type of scenario. The innovator cannot simply take the old formulae and keep rehashing it. That requires learning and new input. There has to be a degree of adaptation of existing knowledge to develop new approaches. The innovation process is a learning process, with knowledge as outcome. Market and product testing are done for example, and the product itself is learnt. There is learning along the way and knowledge gained along the way. The innovator may not have to create the knowledge himself.

\section{$Q$ 5.2: Does it in any way relate to knowledge and information already embedded in existing value} offerings? If so, how?

An innovation is typically an improved answer or an improved offering to something existing. Not building on something implies a completely new thing. In many cases, innovation builds on an understanding of customers in terms of previous products. In many ways, it is not about reinventing the wheel, but just making 
the wheel round where it is square. Understanding what is currently available and being offered, and how it is delivered, helps to understand the need or opportunity, and helps to limit waste during innovation - reinventing wheels.

The innovator may need a point of reference. At the same time, innovation may only require a new or fresh viewpoint. To identify the need is not that hard, but it may be difficult to find a truly new, interesting, useful product that can satisfy and fulfil consumers.

\section{Q 5.3: Is it in any way difficult to produce this knowledge or information? How do you source or surface the knowledge or information?}

A base of existing knowledge may be required. The innovator can approach experts, can self-learn, and can gain experience himself. He can also acquire the necessary skills. It may take a lot of effort - reading, research, and communicating with the relevant people, for instance. Yet, the view of this perspective is that it is just a matter of time and investment before the innovator is successful. The innovator needs a clear understanding of what he wants to do or achieve. The innovator may utilize and exploit the knowledge already available as best as he can, but there will still be an amount of learning, and trial and error.

It may also depend on how well developed the market or industry is. The applications and customer, as well as what works - the product and how to deliver the product - may be well understood already. The industry and market may be continuously learning and developing. Certain knowledge or information may only be produced or released through trust relationships that takes time to develop.

Even if the innovator did and does research, his understanding of the customer's need and the opportunity may be limited. The end result may not be what the customers wanted or expected. The innovator must be positioned, equipped and enabled to recognize both opportunities and solutions to opportunities. The innovator can easily walk past an opportunity or solution.

Freedom to innovate, clustering innovation and competition in innovation, and being first to better understand the customer, to identify trends and changes in the industry or market, and to recognize new opportunities, also from different avenues, are also seen as important enabling factors. The relevance and possible increasing relevance of dreaming and science fiction are mentioned. Some of the seemingly ridiculous ideas in science fiction increasingly become reality over time.

$Q$ 5.4: What is the scope of the knowledge or information you utilize to innovate? Do you incorporate diverse sources of knowledge or information, and do you extend far from the areas or fields known to you? Do you keep with related fields, or do you consider unrelated fields?

Typically, the innovator's idea will start as an improvement on something. Hence, he is drawing from related fields. At the same time, he must break away from traditional thinking and look at other ideas. Unrelated fields may be unrelated to the innovator's existing knowledge, but may very well be related to the gap he has identified. The wider the innovator ventures, the more distinct environments, situations, settings and circumstances he interacts with and interprets. This helps him to see new things and new ways of solving problems. At the same time, the wider the innovator ventures, the less knowledge he has and the more the risk increases. The innovator may shy away from venturing too far, as the risk may get too much. Also, the innovator may prefer to keep to the scope of knowledge he has, to really focus and specialize in something or some area. If the innovator ventures outside of his field, a basic knowledge of the other fields helps to manage the opportunity, and can improve its success.

It is noted that, although there are diverse fields and sources to draw from, the innovator must understand his own industry and market first. The more an innovator learns about an industry, the easier it may become for him to innovate in the industry. Innovators are also able to find application for knowledge and information from decades ago, and from markedly different industries. The knowledge and information also shape their way of thinking, develop their problem solving, and provide them with solutions to problems.

The customer may not really be sure what he wants. The innovator typically attempts to understand the context, situation and environment of the customer, discover what the customer wants and expects, and to get some criteria from the client. He may also focus on frustration - what is currently frustrating the customer, for example. Innovators frequently draw from experts. The innovator may stick with the fields of knowledge he feels comfortable with, and simply pull in experts for other fields of knowledge. Cross-pollination between industries or fields is also very beneficial and rewarding. Linkages are created and brought in to see how it can be integrated into the existing body of knowledge to come up with a new solution.

Q 6.1: When searching for and identifying opportunities, do you actively make an attempt to search for opportunities, or do the opportunities rather register with you? In the case of the former, how do you 


\section{search for opportunities?}

Innovators can stumble upon ideas, but this may be the minority of cases. In general, a structured, formal process is followed, and teamwork may be crucial. It can happen that innovators get ideas in areas outside of his field of knowledge, but most of the time the ideas derive from the interests, passions, personal needs or personal experiences of the innovator, or something he wishes to understand, solve or improve. It may be a factor of the creativity of the innovator - whether he prefers to stick with attempting to innovate something existing or familiar to him. The execution of the idea is seen as far more important and vital than the idea itself.

Innovators frequently identify opportunities through environmental scanning - ongoing research of their business environment. It involves continual interaction and research, and actively pursuing information gathering on a day to day basis - flinging out nets into areas particular to the market and industry, and literally absorbing information. They clue-hunt and peruse existing information to identify new opportunities. They also look for gaps, and whether they would be able to fill the gap.

Innovators study their customers and their needs, and the innovator may discover opportunities as he interacts with customers. They search how they can further benefit the customer. They co-experience or recognize problems and difficulties - "pain" - customers' experience, and use this to devise opportunities. They borrow from other fields and industries. Customers may equally approach the innovator, or the innovator may also acquire opportunities through marketing - putting their competencies or initial ideas out in public.

Q 6.2: In your opinion, is it more difficult to source or identify opportunities, or to develop them at least to a basic concept or prototype? Kindly motivate.

Some saw value in the initial idea. It is very easy to copy; it is very difficult to come up with something new. The new unique concept is the difficult thing to source. Once the innovator has a concept or idea, it is merely a question of time and money to develop it. Enhancements come over time and through the innovation process. Not all agreed that the idea phase is difficult. The innovator only needs to spend time to understand the customers and the industry, and to find the necessary information. The innovator may identify an opportunity. At the same time, an opportunity may come to him.

Others saw more value in the implementation of the idea, than the idea itself. It may be easy to come up with an idea. Rather, to develop the idea is much more important. Most of the time, what the innovator ends up with differs significantly from the initial idea he started off with. The idea is seen as only the starting point, and emphasis is rather placed on how the idea evolves. A lot of shaping and shifting can occur during the implementation process, and a lot of necessity and challenges may emerge out of the implementation process.

In certain markets, it may be difficult to build on existing products, and it may be easier to rather start from scratch. The electronics industry serves as an example. This increases the importance of the idea.

Identifying opportunities requires creativity - something new the innovator sees or imagines the first time. For this the innovator needs to be open, inquisitive and exertional. Developing opportunities requires an actual implementation of the opportunity - making it happen. For this the innovator requires determination. At the same time, ideas can easily be given to experts to implement.

Q 6.3: It is possible to know or discern in advance that an opportunity may only be incremental, or that the opportunity may indeed be radical in terms of outcome?

It is noted that the bulk of opportunities tend to be incremental in nature - innovators predominantly engage in incremental innovation. Some believe that it is possible to know in advance whether an opportunity would be successful. Others feel it can only be conviction, and that the innovator merely acts out of conviction. There are many great opportunities that have never realized, and there are many seemingly foolish or stupid products that had enormous success. There are also many very successful innovations that were not necessarily original - the first instance.

A prominent view is that a lot of innovation is faith or conviction based. The innovator can have a totally unique product that is high in demand, yet there are many different facets that go hand in hand with the success of the product and its delivery. Although he may have a hunch, the innovator can never be certain. Intuition and so forth come to play - the innovator has a feeling or sense regarding the success of the product. The product makes sense in so many ways. Yet, it is faith or conviction based. The innovator believes the product and its implementation, production and delivery will be successful, and acts based on this. He may engage in more marketing or market research, but at some point he needs to balance his resource allocation and spending, and needs to act. Waiting to long may allow others to act on the opportunity instead, or the market may change.

The innovator may not be certain about the eventual implementation success, or customer response. 
The adoption of the new innovation may be slow and incremental, even though the value proposition is distinct. Also, the market may change in the meantime. Other players also recognized the opportunity and pursued it as well. Major players may decide to take over an opportunity. Timing may be important. Some innovations may simply be opportune. An innovation may be too early. The innovation may be too slow to reach the market time to market was too long. The conditions must be right. The innovator may do everything right, but something outside of his control can go wrong.

It may also depend on whether the innovator actually engaged in incremental or radical innovation.

Q 6.4: Is it more difficult to source or identify radical opportunities than incremental opportunities?

One view was that, because radical opportunities are so different, they are easier in the sense of implementation and success. Radical opportunities have a greater chance of success. Yet, to balance the risk, also in the sense of sustainability, incremental innovation may be necessary too.

Another view was that, per definition, radical opportunities are more difficult. The opportunity itself must be radical, and it may be difficult to source such opportunities. The innovator must be very open-minded to conceive something that does not exist in some form yet, or that is totally different from what already exists. Radical innovation may require a lot more intellectual work, and the innovator can not necessarily simply reference what is before him - what already exists. It is easier to making something incrementally or marginally better, than to conceptualize a radical change to an industry. Radical innovation typically (has to) change the whole industry, customer behaviour, and customer preference or acceptance - product reputation. The innovator has a lot less information to work from, particularly in terms customers and the market - customer needs and perceptions, product reception by customers, and eventual market size. Incremental opportunities abound around the innovator and in his environment - the innovator merely needs to look around him - whilst radical opportunities are scarcer. In line with the above, the risk and reward of radical innovation is seen as higher than incremental innovation. If the opportunity is a success, the possibility of market dominance is higher.

Also, even if radical opportunities are pursued, the innovation process may be (becoming) incremental in nature, particularly the more customer input is used, to reduce risk, and to speed up and improve the innovation process.

The recurring view again surfaced that there are not many things to still radically innovate - do something radically or significantly new in or with.

\section{$Q$ 6.5: When searching for and identifying opportunities, what are the sources of knowledge or information you reference? What are some of the things you look at or look into?}

One view was that innovators look at anything and everything. They do environmental scanning and examine the market and industry on a continual basis. The objective is seen to get a very different input as much as possible. Internally, the direction and strategy the innovator or company wants to take, and the strategic objectives or targets it wants to reach, can also define the landscape that is search. Furthermore, the innovator is driven by his passion, interests, values, knowledge and industries.

Innovators continuously assess and communicate with customers, to quickly pick up specific needs. The trick is seen to listen properly. The customer may be conveying the message, but it does not ensure or imply that the business is hearing it. Innovators look at the problems customers and industries experience, how the customer can be benefitted, and whether an opportunity will benefit the customer. They look at ways existing products can be improved, also by improving the properties or characteristics of the product. They also attempt to increase satisfaction and experience - comfort and excitement.

Innovators look at past failures, the reason for the failure, and whether a fresh perspective or direction is not possible. They look at their competitors or the market, to establish whether there is truly room to move on an opportunity. They look at what their suppliers are doing. By collaborating with suppliers, they can create an opportunity for themselves with customers, relative to competitors. They focus on building good relationships with their suppliers. Improving value offerings to the end customer benefits the entire supply chain. Hence, it benefits to cooperate in the supply chain, and to develop the supply chain, particularly through relationships. Opportunities may very well be passed along the supply chain. Innovators also look at other industries.

Experiencing things (doing things), examining people (customers) and how they experience things (human psychology), reading, researching, networking, keeping your ears on the ground and examining patents, were mentioned as specific activities. Technical people and experts, people who used to work in an area or on a problem, networks, trade shows, patents, nature, and everyday life were mentioned as specific sources. 


\section{$Q 6.6$ Is it in any way difficult to source the knowledge or information? How do you source or surface the knowledge or information?}

It may be as simple as personal observation - people often ask themselves why they have not thought of a particular invention. And it may be as simple as acting on an opportunity - people often realize that they had a similar idea regarding a successfully implemented opportunity for a long time.

Innovators can easily work on things and fields they have not necessarily been exposed to before. They are able to easily conduct general searches, particularly by reading up and through the internet, and when they get stuck, they approach and consult experts. They benefit from fast, easy and extensive access to real time information, statistical data, and academic research that has been done. Innovators can simply learn from their competitors, other industries, and experts.

Rather than being difficult, it is also seen to be about process and resources instead - knowing how to go about, getting it right, and the time and effort required. Doing research may take a lot of time, and the effort and resources increase as the quality and sophistication of the research required increase. A lot of information may be readily available to assess and evaluate opportunities, particularly during the initial phase. However, the effort and cost involved increase, as the opportunity advances and the information required gets more sophisticated and detailed.

It may require that the innovator steps out of his comfort zone, and that he is open to different things and fields. He may have to go to great lengths to find, understand and gain insight into unique experiences. There may be a number of methods for the innovator to get closer to an opportunity, and to increase his interaction with the opportunity. For example, he may spy out or reverse engineer existing or related products, or increase his experience and interaction with existing or related products.

The innovator may need to develop his personality and skill to be able to engage and interact with people, including customers, and obtain information from them. To successfully engage the customer may require process, method and time. He may equally need to build relationships, to create opportunity to cocreate with others. Some form of marketing may also be necessary to get closer to customers.

The opportunity may fail, but may spur other opportunities instead.

$Q$ 6.7: Do you ever consider management or business science, or management or business technology as a viable source of knowledge or technology to incorporate into innovation-as a viable source of opportunity?

Opportunities may equally come from the business or management side. The innovator can benefit from understanding different management practices and business models to his disposal, how other businesses are improving their business processes, and looking at what venture capitalists (currently) see as value. The point was raised that management and innovation are not mutually exclusive. Management and business science can help to better manage innovation projects, and increase the success of opportunities.

It is also seen that too much knowledge and management can be restrictive and a hinderance. It is possible to over-complicate the opportunity or process. The innovation and innovation process must be kept as simple as possible too. A basic level of business management processes may be sufficient. Knowing too much - certain information - may prevent you from moving forward and pursuing opportunities.

$Q 7.1$ Do you think knowledge is important for innovation? If so, what is the role of the innovator or entrepreneur, and what are the opportunities for innovators and entrepreneurs?

Knowledge is seen as the corner stone of innovation. You cannot innovate without knowledge. Yet, it may simply imply business acumen, and knowing how to innovate or how to improve business processes. To make an opportunity to work requires a certain degree of skill and knowledge.

The innovator may build on his existing knowledge base and experience, also industry specific knowledge and experience. On the other hand, the innovator may not be able to compete with knowledge and experience already embedded in an industry, but may very well be competent and better at suggesting alternative avenues to pursue, that essentially innovates the industry, because of his detachment, openmindedness, and the fact that he is not necessarily biased, but free in his thinking.

The innovator may simply be the person who came up with a brilliant idea, without necessarily knowing how to get it going as a business. Or, he may be a person who does not have great ideas, but can identify opportunity and resources, and bring them together. He may be the one who sees the opportunity, and who pulls things (and resources) together and makes it a success. He simply identifies opportunities and channels or directs resources accordingly.

The innovator is the organizer, coordinator, orchestrator, and project owner. It is his brain child. $\mathrm{He}$ 
understands how the whole thing fits together. He is the motivator and driver thereof. He is the visionary, because of his faith and conviction in the opportunity. He is the person taking the risk. He is not necessarily doing it for financial reward, but may be motivated instead by factors like passion, legacy, making a difference and being remembered. He manages the entire innovation cycle and moves the opportunity forward by identifying what he already knows, what is uncertain, and what is required. He organizes funding, technical expertise, market analysis and information, proof of concept and prototypes, revisions, and engages potential customers.

\section{Q 7.2: Do you think educational institutions can help or play a greater role in this regard? Can industry, educational institutions, and innovators or entrepreneurs better cooperate?}

The basic development needs of entrepreneurs are seen as basic knowledge, skills, and experience. The quality offered by entrepreneurship schools and incubators, and the mentorship offered by incubators were disputed. The success of government programs, and the ownership and responsibility taken by government were raised. Also, participation among entrepreneurs themselves was highlighted.

Educational institutions are seen to play a crucial role. But, the responsibility should not rest on just tertiary institutions. It may go back as far as primary school. At tertiary level, there is already a gap in terms of problem solving skills. The relationship between mathematics education and innovation, and the correlation between mathematics education and the innovation status of a country, are suggested. It is seen that mathematics helps to teach problem solving. Pupils can be exposed to and taught innovation, entrepreneurship and product-design (design and manufacturing) subjects, and can engage in technical projects, at secondary school level already. Entrepreneurship and innovation are frequently mentioned and discussed, but hardly seen in practice and real-life. Students can be exposed to the working environment and work-life of entrepreneurs and innovators - a career in entrepreneurship and innovation - more; they may have limited exposure in this regard. This includes practical exposure, also practical exposure to the methods and processes of innovation, and the design of products (how a product originates). People have a low appreciation of technology development in general. Tertiary education is seen as overly focused on specialization and professional fields - studying towards a career. The underlying life model may also be outdated and stereotypical.

The development of intellect and psyche are equally mentioned. People are not taught to evaluate, question, analyse and challenge - in general, to think, to think outside of the box, the processes of thinking, and systematically working through a problem. The analogy of learning and development is used: First, the person learns to read and write; thereafter, he learns to read books, and to read up on subjects; and thereafter he learns to write books himself. Innovation becomes possible when more advanced levels of thinking and reasoning are reached. Development should address fear (fear of being wrong; fear of not getting the exact right answer), a lack of confidence, and passion, particularly as it pertains to entrepreneurship. A more accommodating environment in terms of failure can be created. Children are used as an example and analogy. Children are seen as natural innovators - they try to figure things out with the little bit that they have, and they are not scared of what is going to happen. They apply things together and try things. However, the older they get, the more scared they become of being wrong, or being critiqued or reproached by a superior (someone taken to know more than the particular individual). And soon they start to think like that. Along with persistence and grit, mind-set is seen as one of the main factors that differentiate successful entrepreneurs from unsuccessful entrepreneurs.

The psyche or culture of the institution was also noted. One respondent drew from a survey as to which university has created the most billionaires in the world. Consequently, the culture and environment of the institution and the culture and environment the institution creates were mentioned. The institution can create a culture and environment that free the mind, that stimulate good competition (bringing in the best; competing against other institutions to be the best), that emphasize innovation and leadership, that is forward-thinking and revolutionary, and that seek to solve problems and change the world. Bringing together the best students from diverse backgrounds and industries also stimulates innovation.

Entrepreneurs lack proper practical training, and may lack the appropriate practical exposure. Theoretical work enjoys too much emphasis, and entrepreneurs gain too little experience. Entrepreneurs need to be able to identify opportunities or problems before they are able to innovate. It is noted that it may take the entrepreneur years to gain sufficient experience. The aspirant entrepreneur should be taught the skills how to move an idea forward - how to start and how to commence with the necessary research.

Proper certification was mentioned. Entrepreneur schools that train entrepreneurs in a real life application of markets, and an environment where student entrepreneurs can network, and learn from each other's mistakes, were also suggested. The institution should offer a 2 to 3 year course, with hand-holding and assistance to get the student entrepreneur to start a business while they are in the school, possibly with funding 
assistance. The school or institution should assist them with setting up the business correctly. Venture capitalists and angels that can invest in the businesses while they are still in the growth stages can be brought into the education environment. The funding required to start a business may be a hindrance to entrepreneurship education. Rather than keeping it separate, the educational institution must build into its course an internship and apprenticeship model, to keep it closer to the private sector - companies. It would bring feedback into the course, and would better prepare the student for the workplace.

Points related to business acumen were the ability to build a system, get the right people in place, manage employees, converting employees into team members, and building a business in an industry without real prior knowledge of the particular industry.

The mentors suggested for entrepreneurship schools, government programs and incubators, are qualified business owners with a proven track record ( 2 to 4 businesses, cross-industry) that are able to navigate between different industries.

Entrepreneurs can also come together more. They can improve networking among themselves, and can institute a proper governing body to give direction to the field.

Educational institutions are seen as far separated from the private sector. They can provide more technical assistance and support to entrepreneurs, given their expert knowledge. Industries can cooperate and many industries do - there are conferences and new technology roadshows that make it possible to follow and track an industry. Yet, the most important thing missing is cross-industry cooperation. Industries can learn a lot more from other industries, than from themselves, and this is seen as a big opportunity.

\section{Conclusion}

The factors that impact value are seen as price, needs, expectation, functionality, quality, benefit, satisfaction, prestige, reputation (referral and clout), association, relationship, trust, integrity, and support. However, it is believed that not all these are necessarily primary factors of value. Instead, only 4 primary factors of value are advocated: price, benefit, satisfaction, and experience. This is depicted by figure 2. Quality and customer perceived value are factor composites and are thus not considered primary factors of value.

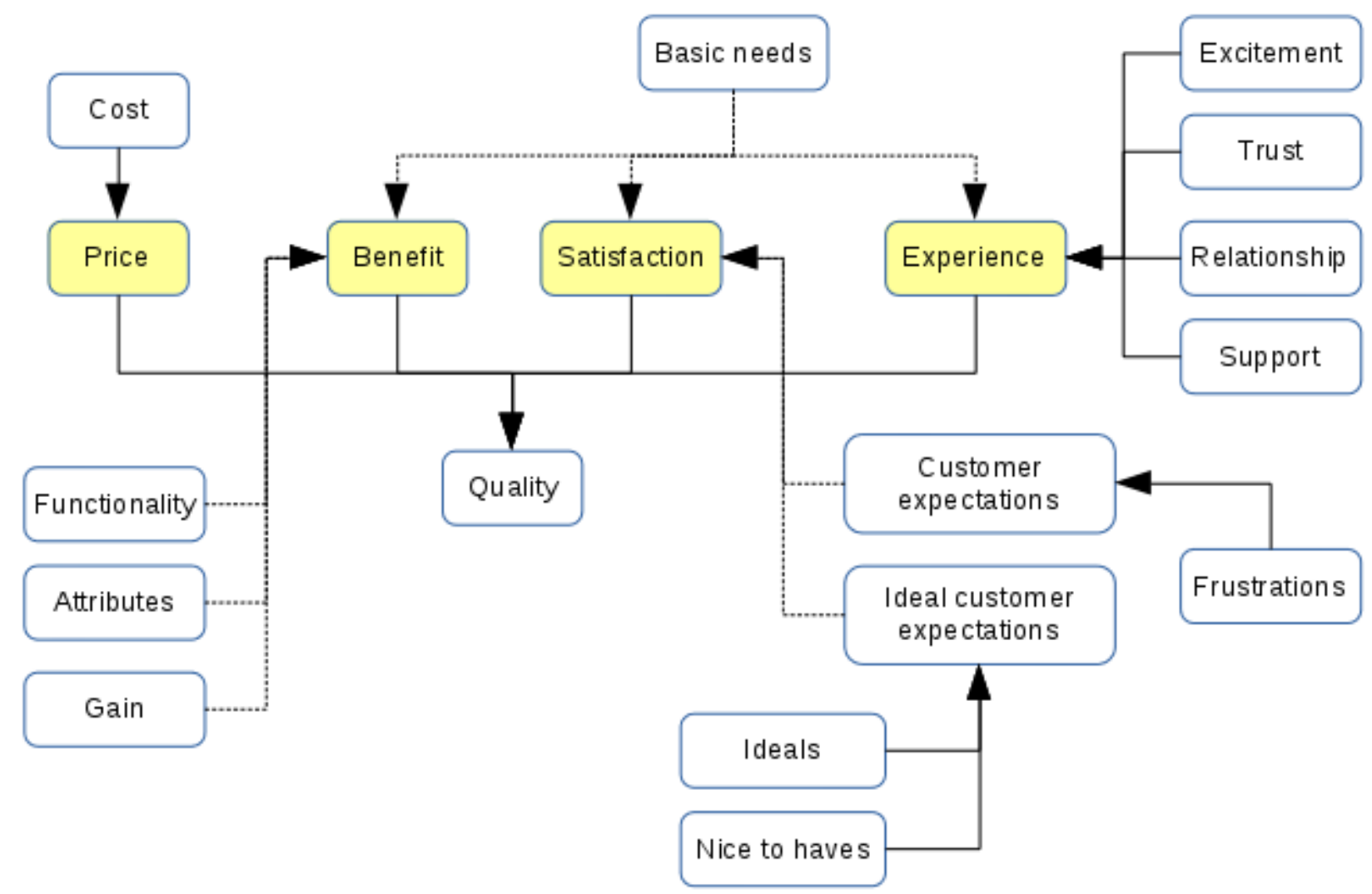

Figure 2. Factors of value

It is also believed that, through the primary factors of value, value created and thus innovation are quantifiable, measurable, and comparable. For example, assuming two products are at par in terms of the other 
(primary) factors (factor homogeneity), product A would create more value than product B, if it a) has a lower price, b) provides more benefit, c) provides more satisfaction, or d) provides a better experience. More specifically, if the benefit, satisfaction, and experience are comparable, product $\mathrm{A}$ has higher value than product $\mathrm{B}$, if it has a lower price. Or, if the price, satisfaction, and experience are comparable, product $\mathrm{A}$ has higher value than product $\mathrm{B}$, if it provides more benefit. Factor heterogeneity and the number of dimensions (4) complicate value comparisons. Innovators can target any of the 4 primary factors of value to create value and to create unique value offerings.

Value creation is customer-centric and requires a proper understanding of the customer, his needs, circumstances and environment. It may also involve the psyche of the customer. It requires a unique value proposition, benefitting the customer, and meeting the customer's expectations. Value can also be created through the customer's experience, including relationship with the customer. The concept of missing value was surfaced - expectations not necessarily explicitly expressed by the customer, that in turn can significantly impact the perceived value of the product, when addressed.

Basic needs may underpin value, yet the relationship is complex. Basic needs are not the only factor that impacts value, and basic needs likely do not impact value directly, but only indirectly. Also, the concept of basic needs in itself is complex, and current treatments thereof may be too primitive.

A number of factors impact the adoption of new value offerings. In general, customers are seen as predominantly purposeful and rational. Yet, there may be cases where customers act impulsively. Customers can be persuaded and manipulated, and their purchase journey may be influenced. The customer may not always know what he wants, may only make primitive value comparisons, and may not always perceive, recognize or acknowledge the value proposition being offered. Customers may purchase the product that satisfy their expectations, without necessarily considering other offerings in detail. Customers may only switch to a different product when they are no longer satisfied with a product, their expectations are no longer met, or the relationship is damaged. Also, there may be a cost involved for the customer in considering other offerings. Customers may be open to suggestion, or may fall into behavioural patterns, and become familiar and attached or associated with products - show loyalty.

New products may need to compete with existing products; new products may equally disrupt the market and status quo. It is seen to depend on the uniqueness of the value offering, and whether the customer perceives or recognizes the value offering.

The market provides clear feedback on the uniqueness of a product. Actual sales, customer feedback (including informal feedback), after-sales service, brand reputation, customer acquisition and retention were seen as ways to gauge the uniqueness of a product. The uniqueness of the product can also be increased by ensuring sufficient distance from competitors' value offerings, building relationships, and building a brand.

Customers' perception of value can aid the innovation process, but it may come with difficulties. The customer must be provided with a concept or prototype, his perceptions may not be completely formed, and may develop, and is only really crystallized with the final product. The customer's perception of value, his needs, circumstances, and environment must be understood. Also, the interaction with the customer, and the transfer of information from the customer, may be complex and sophisticated.

Innovators may not necessarily face a knowledge barrier when wanting to innovate. Knowledge is not necessarily required to innovate. The ability to innovate is seen as a general skill, and the passion, interest, drive and desire of the innovator to innovate is a primary starting point. The innovator may only need an idea, or may only need to identify a problem, and can simply recombine existing knowledge to innovate. Although skills influence the implementation, and even though the innovator may not have the technical know-how to address an opportunity, he may be skilled in overcoming this barrier. He may have business skill in acquiring and pulling the required skills together, or partnering with others. He may approach experts, or may simply self-learn the necessary skills, and gain experience himself. Mere knowledge of how to get an idea going may be enough. Yet, innovation typically improves on what already exists, and a point of reference may be required. The innovator can build on and can be inspired by knowledge of the existing value offerings and value environment. Some basic knowledge regarding an industry, market, customers and existing products may be necessary to innovate. The amount of knowledge required may also be a function of the sophistication of value already embedded in the market. In addition, actual implementation of ideas carries a cost in terms of time, effort and resources required. Also, the innovator may prefer to stick to his areas of knowledge and interest. Knowledge is generally created through the innovator process.

The innovator must be positioned, equipped and enabled to recognize both opportunities and solutions to opportunities. The innovator can easily walk past an opportunity or solution. The innovator draws from both related and unrelated fields. The wider the innovator ventures, the more distinct environments, situations, settings and circumstances he interacts with and interprets. This helps him to see new things and new ways of 
solving problems, but it increases the risk. Also, the innovator may prefer to limit his scope, to really focus and specialize in something or some area.

The innovator may identify an opportunity. At the same time, an opportunity may come to him. Some innovators value the initial idea, and focus on an unique concept. Others see the execution of the idea as far more important than the idea itself, because the idea may significantly evolve during the implementation process. Innovators can stumble upon ideas, but this may be the minority of cases. In general, a structured, formal process is followed, and teamwork may be crucial. It can happen that innovators get ideas in areas outside of their field of knowledge, but most of the time the ideas derive from the interests, passions, personal needs or personal experiences of the innovator, or something he wishes to understand, solve or improve. It may be a factor of the creativity of the innovator - whether he prefers to stick with attempting to innovate something existing or familiar to him.

Innovators may not know in advance how successful their opportunity will be. They may have a sense of the potential, and generally act out of conviction. A number of factors can influence the success of the opportunity, the conditions must be right, and there may be factors outside the contol of the innovator.

It is not agreed that radical opportunities necessarily carry greater risk. Radical opportunities have greater potential, and this may equally imply a risk reduction. Radical opportunities may be more difficult than incremental opportunities, because they require a lot more intellectual work, and it may be difficult to come up with something that is fundamentally new or different. The innovator also has less market- and customerrelated knowledge and information to work from.

Innovators proactively and continuously interact with their environments. They are also influenced by their interests, passions, values, knowledge, industries, and their own objectives and strategies. The knowledge and information innovators collect, shape their way of thinking, develop their problem solving, and provides them with solutions to problems. They find their knowledge and information from diverse sources. It may equally involve personal interaction, encounters and experiences (experiencing). Innovators are also able to find application for knowledge and information from decades ago, and from markedly different industries.

Innovators can easily work on opportunities and fields they have not necessarily been exposed to before. The skills and process of implementation, and determination are emphasized instead.

A number of factors are taken to impact the development of innovators and entrepreneurs, and education is seen to play a role in this. The psychological development of innovators, their intellectual development (thinking that is conducive to innovation), their environments, and their education environments were also highlighted as factors that contribute to their success. It is suggested that institutions may encourage a life model that is not conducive to innovation and entrepreneurship. Young people as the next generation of entrepreneurs, can benefit from more exposure to innovation and entrepreneurship, particularly in terms of career opportunities, work-life, method, and process. The practical training and exposure of entrepreneurs are seen to lack. It is further recommended that entrepreneurs better collaborate among themselves, that industries engage in cross-industry cooperation, and that educational institutions decrease their distance from the private sector, by accommodating entrepreneurs more, and providing expert skills to them.

\section{References}

Adams, R. M., 1997. Social Contexts of Technology. Social Research, 64 (3), pp. 947-964.

Ahuja, G. and Katila, R., 2004. Where do resources come from? The role of idiosyncratic situations. Strategic Management Journal, 25(8-9), pp.887-907.

Alkire, S., 2002. Dimensions of Human Development. World Development, Vol. 30, No. 2, pp.181-205.

Anderson, E. W. and Sullivan, M. W., 1993. The Antecedents And Consequences Of Customer Satisfaction For Firms. Marketing Science, 12 (2), pp. 125-143.

Babin, B. J., Griffin, M., 1998. The nature of satisfaction: an updated examination and analysis. Journal of Business research, 41 (2), pp.127-136.

Bernard, L. C., Mills, M., Swenson, L. and Walsh, R. P., 2005. An Evolutionary Theory of Human Motivation. Genetic, Social, and General Psychology Monographs, 131(2), pp.129-184.

Beukel, K., Valentin, F. and Jensen, R. L., 2014. How Search in Science Impacts on the Value of Inventions at Early and Late Stages in the R\&D cycle. DRUID Society Conference.

Bigné, J.E., Andreu, L., Gnoth, J., 2005. The theme park experience: An analysis of pleasure, arousal and satisfaction. Tourism management, 26(6), pp.833-844.

Brooks, H., 1994. The Relationship between Science and Technology. Research Policy, 23, pp.477-486.

Cao, G. H., 2015. Science-Technology Relationships in Sino-Western Philosophies of Technology: Hints for Innovation, Competitiveness, and Policy. Journal of General Philosophy, 2(1), pp.10-26. 
Chen, S. and Quester, P. G., 2005. Developing a Value-Based Measure of Market Orientation in an Interactive Service Relationship. Journal of Marketing Management, 21, pp.779-808.

Chulef, A. S., Read, S. J. and Walsh, D. A., 1991. A Hierarchical Taxonomy of Human Goals. Motivation and Emotion, Vol. 25, No. 3, pp. 191-232.

Courtney, H., Kirkland, J. and Viguerie, P., 1997. Strategy under uncertainty. Harvard Business Review, 75(6), pp.67-79.

Doyal, L., and Gough, I., 1991. A theory of human need. Basingstoke: Macmillan.

Earle, W. J., 1992. Introduction to philosophy. NY: McGraw-Hill.

Faulkner, W., 1994. Conceptualizing Knowledge Used in Innovation: A Second Look at the ScienceTechnology Distinction and Industrial Innovation. Science, Technology, and Human Values, 19(4), pp. 425-458.

Flint, D. J., Woodruff, R. B. and Fisher Gardial, S., 1997. Customer Value Change in Industrial Marketing Relationships: A Call for New Strategies and Research. Industrial Marketing Management, 26, pp.163-175.

Fournier, S. and Mick, D. G., 1999. Rediscovering Satisfaction. Journal of Marketing. 63(4), pp. 5-10.

Freeman, C., 1994. The economics of technical change. Cambridge Journal of Economics, 18. pp. 463-514.

Gardial, S. F., Clemons, D. S., Woodruff, R.B., Schumann, D. W. and Burns, M. J., 1994. Comparing Consumers' Recall of Prepurchase and Postpurchase Product Evaluation Experiences. Journal of Consumer Research, Vol. 20(4), pp. 548-560.

Halstead, D., Jones, M. A. and Cox, A. N., 2007. Satisfaction theory and the disadvantaged consumer. Journal of Consumer Satisfaction. Dissatisfaction and Complaining Behavior, 20, pp.15

Heilprin, L.B., 1995. Science and Technology: From Prescientific Times to the Present. Journal of the American Society for Information Science, 46(8), p. 574-578.

Holbrook, M.B., 1994. The nature of customer value: an axiology of services in the consumption experience. Service quality: New directions in theory and practice, 21, pp.21-71.

Homburg, C., Koschate, N. and Hoyer, W.D., 2005. Do satisfied customers really pay more? A study of the relationship between customer satisfaction and willingness to pay. Journal of Marketing, 69(2), pp. 84-96.

Hong, S., 1999. Historiographical layers in the relationship between science and technology. History and Technology, 15(4), pp.289-311.

Jensen, M. B, Johnson, B., Lorenz, E. and Lundvall, B.A., 2007. Forms of knowledge and modes of innovation, Research Policy, 36, pp.680-693.

Kahle, L. R., Beatty, S. E. and Homer, P., 1986. Alternative Measurement Approaches to Consumer Values: The List of Values (LOV). and Values and Life Style (VALS). Journal of Consumer Research, Vol. 13, No. 3, pp.405-409.

Keller, K.H., 2008. From Here to There in Information Technology - The Complexities of Innovation. 52 (1). pp. 97-106.

Lee, C., Park, G. and Kang, J., 2016. The impact of convergence between science and technology on innovation. The Journal of Technology Transfer, pp.1-23.

Moliner, M. A., Sanchez, J., Rodriguez, R. M. and Callarisa, L., 2007. Perceived relationship quality and postpurchase perceived value - An integrative framework. European Journal of Marketing, Vol. 41 No. 11/12, pp.1392-1422.

Mullins, J. W. and Forlani, D., 2005. Missing the boat or sinking the boat: a study of new venture decision making. Journal of Business Venturing, 20, pp. 47-69.

Narayan, D. Patel, R., Schafft, K., Rademacher, A. and Koch-Schulte, S., 2000. Voices of the poor: Can anyone hear us. New York: Oxford University Press for the World Bank.

Nelson R. R. and Wright, G., 1992. The Rise and Fall of American Technological Leadership: The Postwar Era in Historical Perspective. Journal of Economic Literature, 30(4), pp.1931-1964.

Nussbaum, M. C., 2000. Women and human development: The capabilities approach. Cambridge: Cambridge University Press.

Oliver, R. L., 1980. A Cognitive Model of the Antecedents and Consequences of Satisfaction Decisions. Journal of Marketing Research, Vol. 17, No. 4. pp. 460-469.

Pannell, D. J., 1999. On the balance between strategic-basic and applied agricultural research. The Australian Journal of Agricultural and Resource Economics, 43(1). pp. 91-113.

Patterson, P., G. and Spreng, R. A., 1997. Modelling the relationship between perceived value, satisfaction and repurchase intentions in a business-to-business, services context: an empirical examination. International Journal of Service Industry Management, Vol. 8, No. 5, pp. 414-434 
Pavitt, K., 1998. The social shaping of the national science base. Research Policy, 27, pp. 793-805

Price, D. J., 1965. Is Technology Historically Independent of Science? A Study in Statistical Historiography. Technology and Culture, 6(4), pp.553-568.

Ravald, A. and Grönroos, C., 1996. The value concept and relationship marketing. European Journal of Marketing, Vol. 30, No. 2, pp. 19-30.

Rip, A., 1992. Science and technology as dancing partners. In Technological development and science in the industrial age. pp. 231-270.

Rosenberg, N. and Nelson, R. R., 1994. American universities and technical advance in industry. Research Policy, 23, pp. 323-348.

Schwartz, S.H., 1992. Universals In The Content And Structure Of Values: Theoretical Advances And Empirical Tests In 20 Countries. In: M. Zanna (Ed.), Advances in Experimental Social Psychology, Vol. 25 New York: Academic Press, pp.1-66.

Sheth, J. N., Newman, B. I. and Gross, B. L., 1991. Why We Buy What We Buy: A Theory of Consumption Values. Journal of Business Research, 22(1), pp. 59-170.

Sinha, I., DeSarbo, W. S., 1998. An Integrated Approach toward the Spatial Modeling of Perceived Customer Value. Journal of Marketing Research, Vol. 35, No. 2. p. 236-249.

Snoj, B., Korda, A. P. and Mumel, D., 2004. The relationships among perceived quality, perceived risk and perceived product value. Journal of Product and Brand Management, 13(3), pp. 156-167.

Spreng, R. A., MacKenzie, S. B. and Olshavsky, R. W., 1996. A Reexamination of the Determinants of Consumer Satisfaction. Journal of Marketing, 60(3), pp. 15

Suenaga, K., A., 2016. A Diagrammatic Model of Technological Paradigms and Technological Trajectories: The Emergence and Hierarchy of Technological Paradigm [online] Available at: http://www.aomevents.com/media/files/ISS\%202012/ISS\%20Parallel\%20Sessions\%20/Suenaga.pdf [Accessed on 16 August 2017].

Sweeney, J.C. and Soutar, G. N., 2001. Consumer perceived value: The development of a multiple item scale. Journal of Retailing, 77, pp. 203-220

Szymanski, D. M. and Henard, D. H., 2001. Customer Satisfaction: A Meta-Analysis of the Empirical Evidence. Journal of the Academy of Marketing Science, 29(1), pp.16-35.

Woodruff, R. B., 1997. Customer value: The next source for competitive advantage. Journal of the Academy of Marketing Science. 25(2), pp.139-153.

Woodruff, R., B., Schumann, D., W. and Gardial, S. F., 1993. Understanding value and satisfaction from the customer's point of view. Survey of Business, 29(1), p. 33-34.

$\mathrm{Xu}$, Y., Goedegebuure, R. and Van der Heijden, B., 2007. Customer Perception, Customer Satisfaction, and Customer Loyalty within Chinese Securities Business. Journal of Relationship Marketing, 5(4), pp.79104.

Yang, Z., and Peterson, R. T., 2004. Customer Perceived Value, Satisfaction, and Loyalty: The Role of Switching Costs. Psychology \& Marketing, 21(10), pp.799-822.

Yüksel, I., 2012. Developing a Multi-Criteria Decision Making Model for PESTEL Analysis. International Journal of Business and Management, 7 (24), pp.52-66.

Zeithaml, V. A., 1988. Consumer Perceptions of Price, Quality, and Value: A Means-End Model and Synthesis of Evidence. Journal of Marketing, 52(3), pp.4-22. 